\title{
Changes in regional climate extremes as a function of global mean temperature: an interactive plotting framework
}

\author{
Richard Wartenburger ${ }^{1}$, Martin Hirschi ${ }^{1}$, Markus G. Donat ${ }^{2,3}$, Peter Greve ${ }^{4}$, Andy J. Pitman ${ }^{2,3}$, and \\ Sonia I. Seneviratne ${ }^{1}$ \\ ${ }^{1}$ Institute for Atmospheric and Climate Science, ETH Zurich, Zurich, Switzerland \\ ${ }^{2}$ ARC Centre of Excellence for Climate System Science, University of New South Wales, Sydney, Australia \\ ${ }^{3}$ Climate Change Research Centre, University of New South Wales, Sydney, Australia \\ ${ }^{4}$ International Institute for Applied Systems Analysis (IIASA), Laxenburg, Austria
}

Correspondence to: Richard Wartenburger (richard.wartenburger@env.ethz.ch) and

Sonia I. Seneviratne (sonia.seneviratne@ethz.ch)

Received: 6 February 2017 - Discussion started: 21 February 2017

Revised: 27 June 2017 - Accepted: 19 August 2017 - Published: 29 September 2017

\begin{abstract}
This article extends a previous study (Seneviratne et al., 2016) to provide regional analyses of changes in climate extremes as a function of projected changes in global mean temperature. We introduce the DROUGHT-HEAT Regional Climate Atlas, an interactive tool to analyse and display a range of well-established climate extremes and watercycle indices and their changes as a function of global warming. These projections are based on simulations from the fifth phase of the Coupled Model Intercomparison Project (CMIP5). A selection of example results are presented here, but users can visualize specific indices of interest using the online tool. This implementation enables a direct assessment of regional climate changes associated with global mean temperature targets, such as the 2 and $1.5^{\circ}$ limits agreed within the 2015 Paris Agreement.
\end{abstract}

\section{Introduction}

The 2015 United Nations Climate Change Conference in Paris (COP21) recently set the goal of limiting global mean temperature increases to "well below 2 degrees" and to pursue efforts to limit warming to $1.5^{\circ} \mathrm{C}$ above pre-industrial levels. Despite this global agreement, the implications of these global mean temperature thresholds have not been fully assessed. Specifically, stakeholders, decision-makers, and the public need more detailed information with respect to associated changes on regional scales, in particular for extreme events and impacts on humans and ecosystems (e.g. Seneviratne et al., 2016, hereafter S16; see also, e.g. Schleussner et al., 2016; Guiot and Cramer, 2016; James et al., 2017).

Numerous approaches have recently been developed for identifying regional climate signals associated with specific global warming targets (James et al., 2017). The technique used in S16 and this study is an empirical sampling approach, which, contrarily to pattern scaling (e.g. Huntingford and Cox, 2000; Mitchell, 2003; Tebaldi and Arblaster, 2014; Lopez et al., 2014), does not require a priori assumptions on the dependency on global mean temperature (or other climate variables; e.g. Frieler et al., 2012; Lynch et al., 2017; Kravitz et al., 2017). Namely, the approach used in S16 derives for predefined regions the empirical relationship of changes in regional quantities (e.g. extremes or mean of climate variables, possibly also impacts; S16) as a function of global mean temperature changes based on a range of climate model projections. This approach can be viewed as an "empirical global mean temperature relationship" (hereafter referred to as "functional relationship") technique, which is a type of hybrid approach compared to the four main approaches described in James et al. (2017). S16 has shown that for some extremes (annual maximum and minimum temperature, heavy precipitation events), the ensemble mean response of absolute changes was often found to be linear, consistent with assumptions of some of the pattern scaling literature and results from other publications (e.g. Fischer et al., 


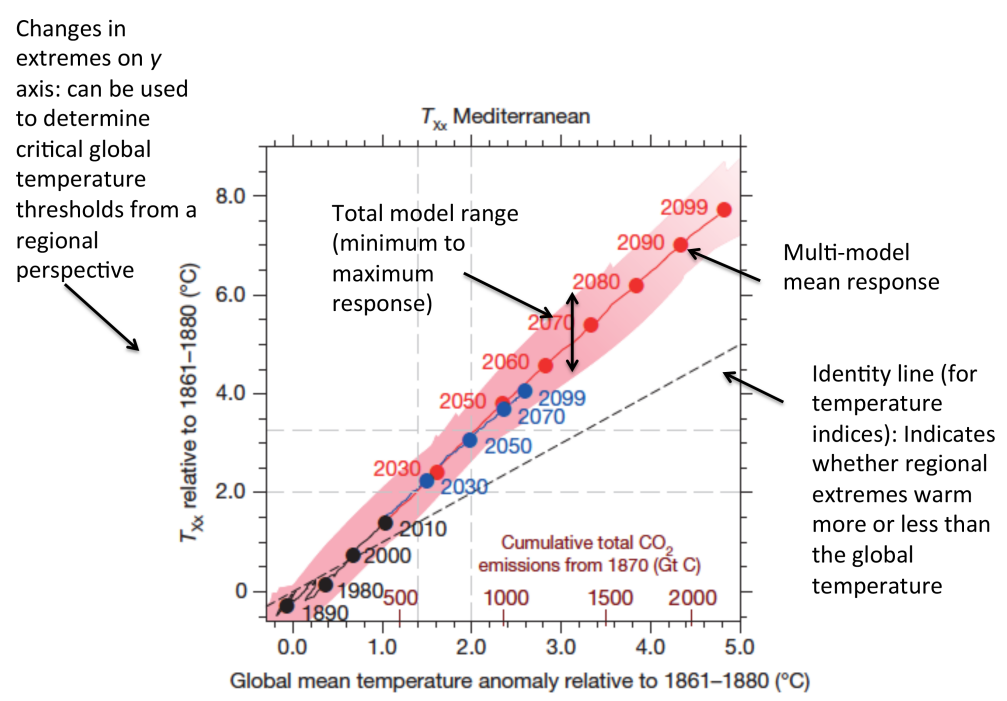

Figure 1. Example of a plot displaying the functional relationship of a regional climate index (annual maximum of daily maximum temperature, $T_{X x}$ ) on global mean temperature following the S16 approach, including explanatory annotations (adapted from S16).

2014). However, this approach also allows to visually assess nonlinearities in the functional relationships.

We provide an illustration of the display used in S16 in Fig. 1. The main advantage of this approach is that it provides, in a single figure, information on (a) the response of a given regional quantity for different global mean temperature (and greenhouse gas emissions) targets, (b) an empirical assessment of this functional relationship (allowing, e.g. to identify its possible (non)linearity), and (c) the range of model and scenario response around this value. Hence, complex information can be more easily conveyed to regional stakeholders, instead of being summarized in several global analyses or provided as time- and scenario-dependent information. While globally aggregated information also has obvious value (e.g. O'Neill et al., 2017), regional information is of critical importance for adaptation and communication.

The S16 study, which focused on temperature and precipitation extremes for two emissions scenarios (RCP8.5 and RCP4.5), identified that much of the absolute changes in temperature extremes and heavy precipitation events could be related almost linearly to the changes in global mean temperature for the time period 1860-2099 (see also Fig. 1), and that this functional relationship was very similar for the two different emissions scenarios. In addition, it highlighted that in absolute terms - changes in regional temperature extremes tended to be much larger than the global mean temperature change. The regional model spread was found to be highly variable depending on the considered quantity and region (S16). We note that all analyses focused on the transient climate response and not on the response at climate equilibrium, which is expected to be substantially different. In addition, it does not consider aspects related to, e.g. overshooting of climate targets or irreversibility in the climate response (Knutti et al., 2016). Moreover, S16 considered changes in absolute temperature extremes and not in the probability of exceeding a given temperature threshold, which by design would tend to change exponentially when mean regional temperature approaches the set threshold (e.g. Fischer and Knutti, 2015 ), even in the case of a linear relationship of the changes in absolute temperature extremes (Whan et al., 2015).

As a follow-up to the S16 study, we provide several new contributions and analyses. First, we introduce a new webbased interactive plotting framework (hereafter referred to as the DROUGHT-HEAT Regional Climate Atlas, available via http://www.drought-heat.ethz.ch/atlas) for the visualization of key functional relationships on global mean temperature, so that the results can be easily shared with other researchers and stakeholders. The DROUGHT-HEAT Regional Climate Atlas has been augmented by several variables compared to the analyses of S16, including responses in regional mean temperature and precipitation and additional climate extremes. In addition, the analyses are performed for all four CMIP5 emissions scenarios (RCP2.6, RCP4.5, RCP6.0, and RCP8.5). These results can be assessed interactively by users online. An overview of the main functional relationships and a comparison with the previous analyses of S16 are discussed in Sect. 3.1. We provide some detailed analyses of specific features of interest for the interpretation of the results. In particular, we assess differences in regional responses at $1.5,2$, and $3{ }^{\circ} \mathrm{C}$ global mean temperature increases in Sect. 3.2. We also assess differences between intra-model spread (i.e. from several realizations of the same model) and inter-model spread for the derived functional relationships in Sect. 3.3. Finally, we provide analyses for regional mean temperature and precipitation based on simulations beyond 
2100 (Sect. 3.4) to assess the links between long-term vs. short-term responses.

\section{Methods and data}

This section presents the data sources and methods used to produce the DROUGHT-HEAT Regional Climate Atlas. It is structured as follows: Sect. 2.1 and 2.2 introduce the set of model simulations and climate and extremes indices which the analyses are based on. The S16 empirical global mean temperature relationship approach is presented in Sect. 2.3. Finally, Sect. 2.4 describes the content and technical implementation of the DROUGHT-HEAT Regional Climate Atlas.

\subsection{Model simulations}

The presented regional-scale functional relationships between a range of indices and global mean temperature are derived from global climate model (GCM) simulations from the Coupled Model Intercomparison Project Phase 5 (CMIP5; Taylor et al., 2012). The subset of GCMs used in this study includes all models for which (a) daily data are available within CMIP5 and (b) climate change indices from the joint CCl/CLIVAR/JCOMM Expert Team on Climate Change Detection and Indices (ETCCDI) are available (Sillmann et al., 2013a, b).

To assess the impact of intra-model spread, we perform our analysis in two steps: using (a) only one ensemble member per model (r1ilp1) and (b) all members available. Similar to S16, we focus on model simulations over the time period 1861-2099, as this is the period covered by virtually all models. For the evaluation of the functional relationship with global mean temperature beyond the end of the century, we also analyse a subset of simulations spanning all years from 1861 to 2299 . For clarity of visual display, we excluded model simulations of the RCP8.5 scenario for which no simulations exist in the historical period. To facilitate the calculation of regional ensemble averages, all GCM output has been bilinearly interpolated to a horizontal resolution of $2.5^{\circ} \times 2.5^{\circ}$. The final set of model simulations employed in this study is listed in Table 1.

\subsection{Climate and extremes indices}

For the ensemble member $e$ of each model $m$ and emission scenario rcpx, we have analysed the 27 ETCCDI core climate change indices $I_{\text {rcpx }, m, e}$, which were downloaded from the Canadian Centre for Climate Modelling and Analysis (CCMA) indices archive (http://www.cccma.ec.gc.ca/ data/climdex/; Sillmann et al., 2013a, b) on 19 May 2016. Similar to the CMIP5 model data, the indices have been interpolated to $2.5^{\circ} \times 2.5^{\circ}$ horizontal resolution.

In addition to the ETCCDI indices, we have computed three drought indices (which can be used to monitor either anomalously dry or anomalously wet conditions) based on soil moisture, precipitation, and evapotranspiration from CMIP5 model simulations (see Sect. 2.1) using the R statistical language and the Climate Data Operators (CDO). The Standardized Precipitation Index (SPI) has been calculated using the SPEI package (https://cran.r-project.org/web/ packages/SPEI, based on Vicente-Serrano et al., 2010) for an accumulation period of 12 months. Soil moisture anomalies (SMAs, given in units of standard deviations in order to be independent on model-specific parametrizations of soil moisture depths) have been derived according to the procedure used in Orlowsky and Seneviratne (2012, 2013), which includes a posterior filtering of SMAs using a median absolute deviation filter. In addition, we provide analyses for changes in precipitation minus evapotranspiration $(P-E)$ as a further measure of changes in land water availability (e.g. Greve and Seneviratne, 2015).

We also include mean temperature $(T)$ and precipitation $(P)$ in our analyses. We do this to assess whether the regional response of extremes is related to the regional mean climate response or rather reflects a specific behaviour of extremes in the regions examined. For simplicity, we also refer to these variables as indices. A complete list of all indices, their data source, and associated units is provided in Table 2.

\subsection{Derivation of the functional relationship between changes in regional climate indices and global mean temperature}

Yearly global mean temperatures $T_{\mathrm{glob}, \mathrm{rcpx}, m, e}$ for emission scenario rcpx have been derived from each ensemble member $e$ of model $m$. Both $I_{\mathrm{rcpx}, m, e}$ and $T_{\mathrm{glob}, \mathrm{rcpx}, m, e}$ are treated as anomalies relative to the pre-industrial reference period of 1861-1880 (subscript ref). For all time steps $t$, we thus compute $\Delta T_{\text {glob,rcpx }, m, e, t}=T_{\text {glob,rcpx }, m, e, t}-T_{\text {glob,rcpx }, m, e, \text { ref }}$ and $\Delta I_{\mathrm{rcpx}, m, e, t}=I_{\mathrm{rcpx}, m, e, t}-I_{\mathrm{rcpx}, m, e, \text { ref }}$. Note that $T_{\mathrm{glob}}$ refers to a model estimate of past and projected future global mean near-surface temperatures which is known to be biased with respect to observation-based global mean temperature records that merge air temperatures over land and sea surface temperatures over the ocean (Cowtan et al., 2015).

We apply a common land-sea mask at $2.5^{\circ} \times 2.5^{\circ}$ to all indices as we focus on (extremes) indices that are meaningful over land. We then compute regionally averaged indices $\Delta I_{\text {reg,rcpx }, m, e}$ using the set of globally distributed regions defined in Chap. 3 of the Special Report on Managing the Risks of Extreme Events and Disasters to Advance Climate Change Adaptation (SREX; Seneviratne et al., 2012, Fig. 3-1 therein), hereafter referred to as SREX regions. We also average the indices over the additional regions defined in S16 as well as over global land (including ice sheets).

To test the significance of the functional relationship between the regionally averaged indices and the global mean temperature signal, we apply an ordinary least squares fit between $\Delta T_{\mathrm{glob}, \mathrm{rcpx}, m, e}$ and $\Delta I_{\mathrm{reg}, \mathrm{rcpx}, m, e}$ for each individual model realization (focusing on $\Delta T_{\text {glob,rcpx }, m, e} \geq 1{ }^{\circ} \mathrm{C}$, which 
Table 1. List of models used in this study (in alphabetical order). Crosses (circles) indicate availability of simulations of the ensemble member r1i1p1 for the 1861-2099 (1861-2299) period. Note that the number of simulations of other ensemble members is considerably smaller.

\begin{tabular}{|c|c|c|c|c|c|c|}
\hline Model & Modelling centre & Historical & RCP2.6 & $\mathrm{RCP} 4.5$ & RCP6.0 & RCP8.5 \\
\hline ACCESS1-0 & $\begin{array}{l}\text { Commonwealth Scientific and Industrial Research Organi- } \\
\text { zation (CSIRO) and Bureau of Meteorology (BOM), Aus- } \\
\text { tralia }\end{array}$ & $\mathrm{x}$ & & $\mathrm{x}$ & & $\mathrm{x}$ \\
\hline bcc-csm1-1 & Beijing Climate Center, China & $\mathrm{x}$ & o & o & $\mathrm{x}$ & o \\
\hline bcc-csm1-1-m & Meteorological Administration, China & $\mathrm{x}$ & $\mathrm{x}$ & $\mathrm{x}$ & $\mathrm{x}$ & $\mathrm{x}$ \\
\hline CanESM2 & $\begin{array}{l}\text { Canadian Centre for Climate Modelling and Analysis, } \\
\text { Canada }\end{array}$ & $\mathrm{x}$ & $\mathrm{x}$ & $\mathrm{x}$ & & $\mathrm{x}$ \\
\hline CCSM4 & National Center for Atmospheric Research, USA & $\mathrm{x}$ & & o & o & o \\
\hline CMCC-CM & Centro Euro-Mediterraneo per i Cambiamenti Climatici, & $\mathrm{x}$ & & $\mathrm{x}$ & & $\mathrm{x}$ \\
\hline CMCC-CMS ${ }^{\mathrm{a}}$ & Italy & $\mathrm{x}$ & & $\mathrm{x}$ & & $\mathrm{x}$ \\
\hline CNRM-CM5 & $\begin{array}{l}\text { Centre National de Recherches Météorologiques/ } \\
\text { Centre Européen de Recherche et Formation Avancées en } \\
\text { Calcul Scientifique, France }\end{array}$ & $\mathrm{x}$ & $\mathrm{x}$ & $\mathrm{x}$ & & $\mathrm{x}$ \\
\hline CSIRO-Mk3-6-0 & $\begin{array}{l}\text { Commonwealth Scientific and Industrial Research Organi- } \\
\text { zation/Queensland Climate Change Centre of Excellence, } \\
\text { Australia }\end{array}$ & $\mathrm{x}$ & $\mathrm{x}$ & o & $\mathrm{x}$ & o \\
\hline FGOALS-s2 & $\begin{array}{l}\text { LASG, Institute of Atmospheric Physics, Chinese Academy } \\
\text { of Sciences, China }\end{array}$ & $\mathrm{x}$ & $\mathrm{x}$ & $\mathrm{x}$ & $\mathrm{x}$ & $\mathrm{x}$ \\
\hline GFDL-CM3 & NOAA Geophysical Fluid Dynamics Laboratory, USA & $\mathrm{x}$ & $\mathrm{x}$ & & $\mathrm{x}$ & $\mathrm{x}$ \\
\hline GFDL-ESM2G & & $\mathrm{x}$ & $\mathrm{x}$ & $\mathrm{x}$ & $\mathrm{x}$ & $\mathrm{x}$ \\
\hline GFDL-ESM2M & & $\mathrm{x}$ & $\mathrm{x}$ & $\mathrm{x}$ & $\mathrm{x}$ & $\mathrm{x}$ \\
\hline HadGEM2-CC & Met Office Hadley Centre, UK & $\mathrm{x}$ & & $\mathrm{x}$ & & $\mathrm{x}$ \\
\hline HadGEM2-ES & & $\mathrm{x}$ & o & & $\mathrm{x}$ & o \\
\hline inmem4 & Institute for Numerical Mathematics, Russia & $\mathrm{x}$ & & $\mathrm{x}$ & & $\mathrm{x}$ \\
\hline IPSL-CM5A-LR & Institut Pierre-Simon Laplace, France & $\mathrm{x}$ & o & o & $\mathrm{x}$ & o \\
\hline IPSL-CM5A-MR & & $\mathrm{x}$ & $\mathrm{x}$ & & $\mathrm{x}$ & $\mathrm{x}$ \\
\hline IPSL-CM5B-LR & & $\mathrm{x}$ & & $\mathrm{x}$ & & $\mathrm{x}$ \\
\hline MIROC-ESM & Japan Agency for Marine-Earth Science and Technology, & $\mathrm{x}$ & $\mathrm{x}$ & $\mathrm{x}$ & $\mathrm{x}$ & $\mathrm{x}$ \\
\hline MIROC-ESM- & Atmosphere and Ocean Research Institute (The University & $\mathrm{x}$ & $\mathrm{x}$ & $\mathrm{x}$ & $\mathrm{x}$ & $\mathrm{x}$ \\
\hline CHEM & $\begin{array}{l}\text { of Tokyo), and National Institute for Environmental Studies, } \\
\text { Japan }\end{array}$ & $\mathrm{x}$ & $\mathrm{x}$ & $\mathrm{x}$ & $\mathrm{x}$ & $\mathrm{x}$ \\
\hline MIROC5 & & $\mathrm{x}$ & $\mathrm{x}$ & $\mathrm{x}$ & $\mathrm{x}$ & $\mathrm{x}$ \\
\hline MPI-ESM-LR & Max Planck Institute for Meteorology, Germany & $\mathrm{x}$ & o & o & & o \\
\hline MPI-ESM-MR & & $\mathrm{x}$ & $\mathrm{x}$ & $\mathrm{x}$ & & $\mathrm{x}$ \\
\hline MRI-CGCM3 & Meteorological Research Institute, Japan & $\mathrm{x}$ & $\mathrm{x}$ & $\mathrm{x}$ & $\mathrm{x}$ & $\mathrm{x}$ \\
\hline NorESM1-M & Norwegian Climate Centre, Norway & $\mathrm{x}$ & $\mathrm{x}$ & $\mathrm{x}$ & $\mathrm{x}$ & $\mathrm{x}$ \\
\hline
\end{tabular}

a Not used for calculation of $P-E$.

roughly represents future projections in the individual model simulations). The number of models for which the slope of the regression line (i.e. the measure of the functional relationship) is significantly different from zero ( $p=0.01$, after controlling the false discovery rate according to Benjamini and Hochberg, 1995, as recently suggested by Wilks, 2016) is used to indicate the robustness of the functional relationship in the ensemble mean of the changes (see Sect. 3). Note that a significant response of an individual model realization implies that the corresponding relationship can be explained by a linear model, though it does not guarantee superiority of the linear model over other, higher-order polynomials. We also test the significance of the differences of changes in between 1.5 and $2^{\circ} \mathrm{C}$ global warming based on all model simulations of a specific index and scenario, using a two-sided paired Wilcoxon test ( $p=0.01$, after controlling the false discovery rate according to Benjamini and Hochberg, 1995).

To filter out short-term climatic fluctuations, a decadal running mean is applied to the anomalies, starting with 1871-1880 (note that the year associated with each running mean period refers to the last year of that period). We then compute the unweighed ensemble mean change of the smoothed indices $\Delta I_{\text {reg,rcpx }}=\overline{\Delta I_{\text {reg, rcpx }, m, e}}$ and the corresponding ensemble mean change of the global mean temperatures $\Delta T_{\text {glob,rcpx }}=\overline{\Delta T_{\text {glob,rcpx }, m, e}}$.

In order to yield common, model-independent values of $\Delta T_{\text {glob }}$ and to provide a bidirectional uncertainty estimate (i.e. including both the inter-model ensemble spread in $\Delta I_{\text {reg,rcpx }}$ and $\left.\Delta T_{\text {glob,rcpx }}\right)$, we perform a spline interpolation of $\Delta I_{\text {reg,rcpx }, m, e}$ to a common temperature axis. The min- 
Table 2. List of indices (in alphabetical order) as presented in the DROUGHT-HEAT Regional Climate Atlas. Crosses denote indices specifically discussed in this paper as well as indices expressed as percent changes relative to the pre-industrial reference period (18611880).

\begin{tabular}{|c|c|c|c|c|c|}
\hline Index & Description & Unit & $\begin{array}{l}\text { Expressed as } \\
\% \text { change }\end{array}$ & $\begin{array}{l}\text { Discussed in } \\
\text { this paper }\end{array}$ & Reference for computation \\
\hline CDD & Maximum length of dry spell & days & & $\mathrm{x}$ & Sillmann et al. $(2013 a, b)$ \\
\hline CSDI & Cold speel duration index & days & & & Sillmann et al. $(2013 a, b)$ \\
\hline CWD & Maximum length of wet spell & days & & & Sillmann et al. $(2013 a, b)$ \\
\hline DTR & Daily temperature range & ${ }^{\circ} \mathrm{C}$ & & & Sillmann et al. $(2013 a, b)$ \\
\hline FD & Number of frost days & days & & & Sillmann et al. $(2013 a, b)$ \\
\hline GSL & Growing season length & days & & & Sillmann et al. $(2013 a, b)$ \\
\hline ID & Number of icing days & days & & & Sillmann et al. $(2013 a, b)$ \\
\hline$P-E$ & Precipitation - evapotranspiration & $m m$ day $^{-1}$ & & $\mathrm{x}$ & Greve and Seneviratne (2015) \\
\hline$P$ & Mean precipitation & $\mathrm{mm}$ & $\mathrm{x}$ & $\mathrm{x}$ & Taylor et al. (2012) \\
\hline PRCPTOT & Annual total precipitation in wet days & $\mathrm{mm}$ & $\mathrm{x}$ & & Sillmann et al. $(2013 \mathrm{a}, \mathrm{b})$ \\
\hline $\mathrm{R} 10 \mathrm{~mm}$ & Annual count of days when $P R C P \geq 10 \mathrm{~mm}$ & days & & & Sillmann et al. $(2013 a, b)$ \\
\hline $\mathrm{R} 1 \mathrm{~mm}$ & Annual count of days when $\mathrm{PRCP} \geq 1 \mathrm{~mm}$ & days & & & Sillmann et al. $(2013 a, b)$ \\
\hline $\mathrm{R} 20 \mathrm{~mm}$ & Annual count of days when $\mathrm{PRCP} \geq 20 \mathrm{~mm}$ & days & & & Sillmann et al. $(2013 a, b)$ \\
\hline R95pTOT & Annual total PRCP when RR $>95 \%$ & $\mathrm{~mm}$ & & & Sillmann et al. $(2013 \mathrm{a}, \mathrm{b})$ \\
\hline R99pTOT & Annual total PRCP when RR $>99 \%$ & $\mathrm{~mm}$ & & & Sillmann et al. $(2013 a, b)$ \\
\hline Rx1day & Monthly maximum 1-day precipitation & $\mathrm{mm}$ & $\mathrm{x}$ & & Sillmann et al. $(2013 a, b)$ \\
\hline Rx5day & Monthly maximum 5-day precipitation & $\mathrm{mm}$ & $\mathrm{x}$ & $\mathrm{x}$ & Sillmann et al. $(2013 a, b)$ \\
\hline SDII & Simple precipitation intensity index & $\mathrm{mm} \mathrm{day}^{-1}$ & & & Sillmann et al. $(2013 a, b)$ \\
\hline SMA & Soil moisture anomalies & 1 & & $\mathrm{x}$ & Orlowsky and Seneviratne (2013) \\
\hline SPI12 & $\begin{array}{l}\text { Standardized Precipitation Index (12-month } \\
\text { accumulation period) }\end{array}$ & 1 & & $\mathrm{x}$ & Vicente-Serrano et al. (2010) \\
\hline SU & Number of summer days & days & & & Sillmann et al. $(2013 \mathrm{a}, \mathrm{b})$ \\
\hline$T$ & Mean temperature & ${ }^{\circ} \mathrm{C}$ & & $\mathrm{x}$ & Taylor et al. (2012) \\
\hline TN10p & Percentage of days when $T_{\mathrm{N}}<10$ th percentile & $\%$ days & & & Sillmann et al. $(2013 \mathrm{a}, \mathrm{b})$ \\
\hline TN90p & Percentage of days when $T_{\mathrm{N}}>$ 90th percentile & $\%$ days & & & Sillmann et al. $(2013 \mathrm{a}, \mathrm{b})$ \\
\hline$T_{N n}$ & Monthly minimum of daily min. temperature & ${ }^{\circ} \mathrm{C}$ & & $\mathrm{x}$ & Sillmann et al. $(2013 a, b)$ \\
\hline$T_{N x}$ & Monthly maximum of daily min. temperature & ${ }^{\circ} \mathrm{C}$ & & $\mathrm{x}$ & Sillmann et al. $(2013 \mathrm{a}, \mathrm{b})$ \\
\hline TR & Number of tropical nights & days & & & Sillmann et al. $(2013 a, b)$ \\
\hline TX10p & Percentage of days when $T_{\mathrm{X}}<10$ th percentile & $\%$ days & & & Sillmann et al. $(2013 \mathrm{a}, \mathrm{b})$ \\
\hline TX90p & Percentage of days when $T_{X}>90$ th percentile & $\%$ days & & & Sillmann et al. $(2013 a, b)$ \\
\hline$T_{X n}$ & Monthly minimum of daily max. temperature & ${ }^{\circ} \mathrm{C}$ & & $\mathrm{x}$ & Sillmann et al. $(2013 a, b)$ \\
\hline$T_{X x}$ & Monthly maximum of daily max. temperature & ${ }^{\circ} \mathrm{C}$ & & $\mathrm{x}$ & Sillmann et al. $(2013 a, b)$ \\
\hline WSDI & Warm spell duration index & days & & & Sillmann et al. $(2013 a, b)$ \\
\hline
\end{tabular}

imum and maximum of the interpolated values (across all model realizations and scenarios) are then used to determine the overall spread of $\Delta I_{\text {reg }}$ relative to $\Delta T_{\text {glob }}$.

\subsection{Plotting framework}

\subsubsection{Content of the plotting framework}

All plots of the regional-scale functional relationships with global mean temperature and related figures similar to those shown in the remainder of this paper are available through the web interface of the DROUGHT-HEAT Regional Climate Atlas. All plots available through this interactive interface are based on the computation of the functional relationship with global mean temperature using the S16 framework as described in the previous section.

The layout and individual components of the DROUGHTHEAT Regional Climate Atlas are shown in Fig. 2. Plots are drawn by making the appropriate selections in the data panel (left-hand side of the screenshot). The first item to select is the diagnostic (i.e. "Functional relationship with global mean temperature" for the results of this study). After that, the data source drop-down menu is populated with a list of available data sets (i.e. CMIP5 model simulations for this study, for either the period 1861-2099 or 1861-2299). Equivalently, the drop-down menu labelled "Select Index or Variable" is filled with available indices. Credits of the selected diagnostic and data source are displayed on the right-hand panel.

The map in the data panel shows the set of regions for which plots of the chosen diagnostic are available (SREX regions for this study). Other region sets can be selected by using the drop-down menu on top of the map (e.g. also further regions used in S16, such as the contiguous US, central Brazil, the Arctic, and southern Asia). Once the user has selected a region (by either clicking on one of the polygons 


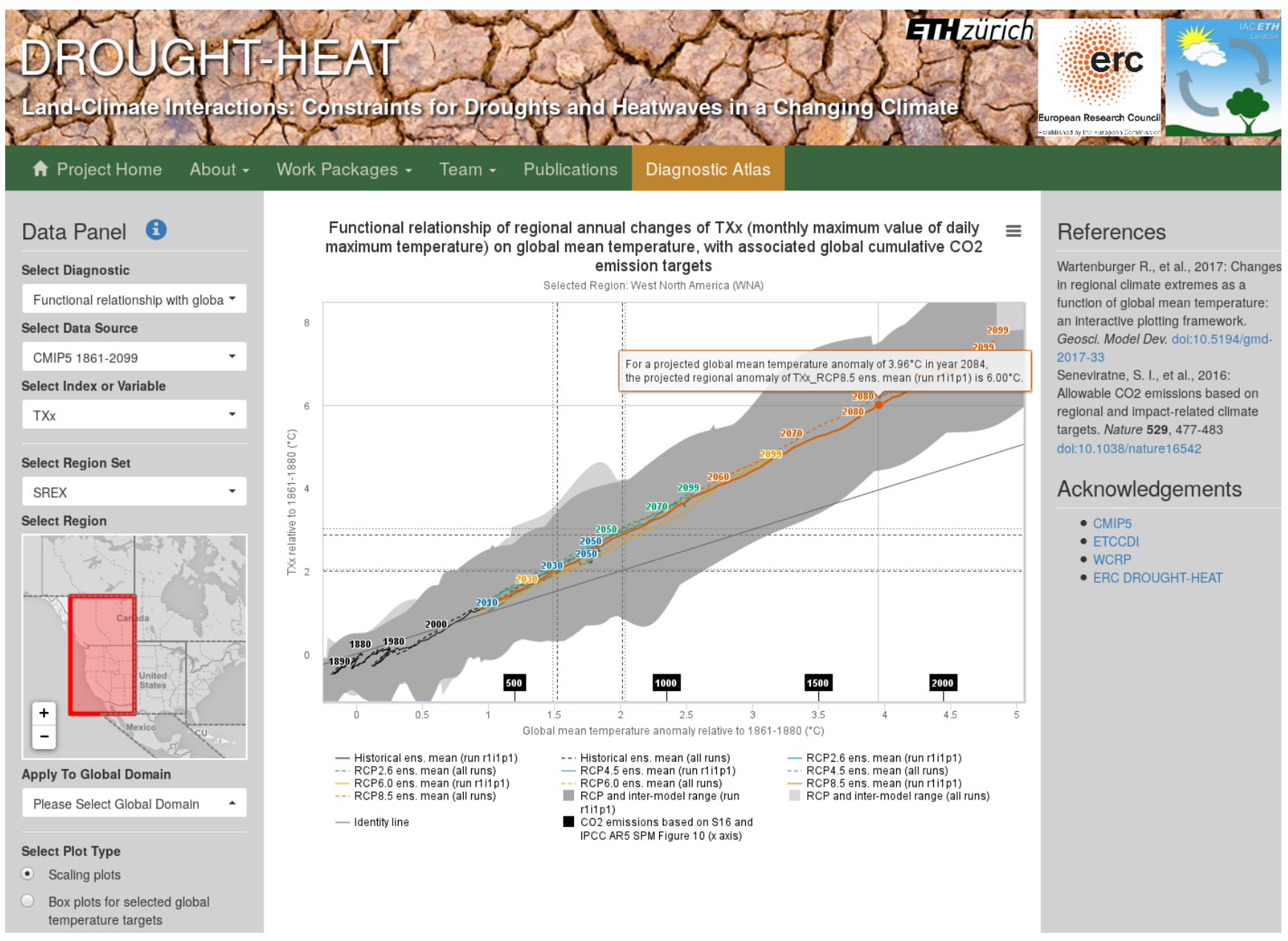

Figure 2. Screenshot of the DROUGHT-HEAT Regional Climate Atlas. For demonstration, this screenshot displays the functional relationship of $\Delta T_{X x}$ on $\Delta T_{\text {glob }}$ based on model simulations from 1861 to 2099 for the SREX region west North America (WNA).

in the map or by selecting a global domain), the requested plot is displayed in the main panel of the website. When the appropriate selections are made, a link appears allowing the user to navigate to a set of box plots showing the distribution of the selected index for fixed global mean temperature targets of 1.5, 2 and $3{ }^{\circ} \mathrm{C}$ (for more details, see Sect. 3.2).

The atlas has been designed to be self-explanatory. Each item in the drop-down lists is accompanied by a short help text that shows up when hovering over it with the mouse. In addition, a pop-up window has been added to provide help for first-time users. Users interested in reusing the results shown in a specific plot can download the related data in comma-separated value (CSV) format.

\subsubsection{Technical implementation of the plotting framework}

The DROUGHT-HEAT Regional Climate Atlas is based on a number of web modules served through the Gunicorn web application server (http://gunicorn.org/) and the
NGINX reverse-proxy server (https://www.nginx.com/). The website is built within the Django web framework (https: //www.djangoproject.com/). It is hosted on a web server at ETH Zurich.

The map shown in the data panel of the DROUGHTHEAT Regional Climate Atlas (see Fig. 2) is based on Leaflet (http://leafletjs.com/). The background (world) layer is based on tilesets served via Mapbox (https://www.mapbox.com/). The region boundaries are read from text files in GeoJSON format.

There are two processing layers required to produce plots within the framework. First, a locally hosted ncl script serves static CSV files to the web server. The script writes the data points of each plot series into files inside a unique folder which represents the diagnostic, region and index. It also generates two customizable files containing plot and series configuration parameters for each index. In the second (server-sided) layer, the CSV files are read and processed by JavaScript code. Finally, the Highcharts charting library 
(http://www.highcharts.com/) parses the input files to generate the desired plot.

\section{Results and discussion}

In the following, we demonstrate the capabilities of the DROUGHT-HEAT Regional Climate Atlas by presenting some selected results. We also discuss some more in-depth analyses considering specific features of the assessed functional relationships between regional climate and global mean temperature changes.

\subsection{Functional form of the relationship}

Figure 3 displays the relations of regional changes in temperature-based climate and extremes indices in various SREX regions to global mean temperature $\left(\Delta T_{\text {glob }}\right)$. The indices show an apparent linear scaling with $\Delta T_{\text {glob }}$ when solely considering the ensemble mean change (the significance of the functional relationship of individual ensemble members is tested below; see Table 3 ). Moreover, the relationship is apparently not influenced by differences in $\Delta T_{\text {glob }}$ among the model simulations (see Fig. A8 in the Appendix). As all indices in Fig. 3 are derived from temperatures, the scaling of changes in these indices shows similar linear features to the scaling of changes in regional mean temperatures ( $\Delta T$, first row of Fig. 3). Besides this, the relationship of these indices to global mean temperature involves the least uncertainties (as measured by the ensemble spread) when compared to the other indices shown in Fig. 4. For all of the indicated regions, the slope of the temperature-based indices is consistently above 1 (although only by a small margin for $\Delta T_{X n}$ in the Amazon region, AMZ, which is also the case in other tropical regions, not shown), indicating a larger change of the regional indices compared to $\Delta T_{\mathrm{glob}}$. For instance, at $2{ }^{\circ} \mathrm{C}$ global warming, the warming in hot extremes $\left(T_{X x}\right)$ in the Mediterranean (SREX region MED) amounts to $3.2^{\circ} \mathrm{C}$. The largest departures from the identity line are found for changes in the annual minimum of both daily maximum and minimum temperatures $\left(\Delta T_{X n}\right.$ and $\left.\Delta T_{N n}\right)$ in north Europe (NEU), which is very well in line with the observed recent decrease in temperature variance in the northern mid-to-high latitudes due to Arctic amplification (Screen, 2014).

For the precipitation-based indices discussed here, the responses are often less pronounced and subject to larger inter-model uncertainties (Fig. 4). Nevertheless, the ensemble mean changes of the purely precipitation-based indices $(\Delta P, \Delta \mathrm{Rx} 5$ day, $\Delta \mathrm{CDD}$, and $\Delta \mathrm{SPI} 12)$ still show a distinct linear scaling with $\Delta T_{\text {glob }}$ in some regions. For example, there is a clear tendency for a positive scaling of heavy precipitation ( $\triangle \mathrm{R} \times 5$ day) with $\Delta T_{\text {glob }}$ in NEU, central Europe (CEU), central North America (CNA), and east Asia (EAS). Moreover, MED displays a remarkable increase in the maximum dry spell lengths $(\triangle \mathrm{CDD})$ by the end of the century (i.e. the decade in which global mean temperature anomalies are projected to reach $\Delta T_{\text {glob }}=4.75^{\circ} \mathrm{C}$ in the RCP8.5 scenario). This is consistent with the response of the drought indices $(\Delta \mathrm{SPI} 12, \triangle \mathrm{SMA}$, and $\Delta P-E)$ in this region towards drying, although the large uncertainties in $\triangle$ SMA near the end of the century must not be ignored. The trends in $\triangle \mathrm{SPI} 12, \triangle \mathrm{SMA}$, and $\Delta P-E$ in AMZ point towards a drying in this region, which is unique among other tropical regions (not shown). However, it must be noted that - apart from the positive scaling of $\triangle$ SPI12 in NEU and EAS and the wetting signal indicated by $\Delta P-E$ in NEU - the responses are connected with large uncertainties and both an increase and a decrease of these indices is within the projected range even for large values of $\Delta T_{\text {glob }}$. Note that the differences between the scaling of mean precipitation and heavy precipitation could possibly be explained by different sensitivities to aerosol loading (Pendergrass et al., 2015).

Overall, the functional relationship is very similar for the four emission scenarios (Figs. 3 and 4). Thus, regional changes in the indicated indices can be usefully related to given cumulative $\mathrm{CO}_{2}$ targets (according to S16), independently of the emission pathway.

Table 3 displays the significant linear trends of the previously discussed indices of the RCP8.5 scenario for $\Delta T_{\text {glob }} \geq$ $1^{\circ} \mathrm{C}$. Models generally agree that changes in global mean temperatures translate into enhanced changes both in regional mean temperatures over land as well as in regional temperature extremes. The scaling with precipitation-derived indices shows a much more diverse pattern. Heavy precipitation events (as reflected by Rx5day) are projected to intensify over several of the selected regions, most strikingly over NEU, EAS, and EAF (east Africa). Dry spells are projected to become longer mainly over MED and AMZ, which is in line with both a decrease in precipitation and enhanced soil moisture depletion as shown by $\triangle$ SMA (although projections of CDD are generally dominated by larger uncertainties, which is in part due to high model sensitivities related to the binary cut-off of $1 \mathrm{~mm}$ used to distinguish dry days from days with precipitation). The Mediterranean region (MED) is the only region for which all relevant indices point towards a distinct drying. In contrast, precipitation is projected to increase with increasing global mean temperatures over NEU, EAS, and EAF. While this signal is consistent with the trend in SPI12 in each of the three regions, soil moisture anomalies are projected to only increase in EAF. Apart from MED, the model agreement on trends in $P-E$ is mostly poor.

\subsection{1 .5 vs. $2^{\circ} \mathrm{C}$ response}

Figures 5 and 6 present the CMIP5-based distributions of the changes in the various indices for $1.5,2$, and $3{ }^{\circ} \mathrm{C}$ global warming, and for the four emission scenarios (Appendix A shows the same type of plots for all other SREX regions as well as for global land; not discussed). Significant differences between 1.5 and $2{ }^{\circ} \mathrm{C}$ global warming (see Sect. 2.3) 

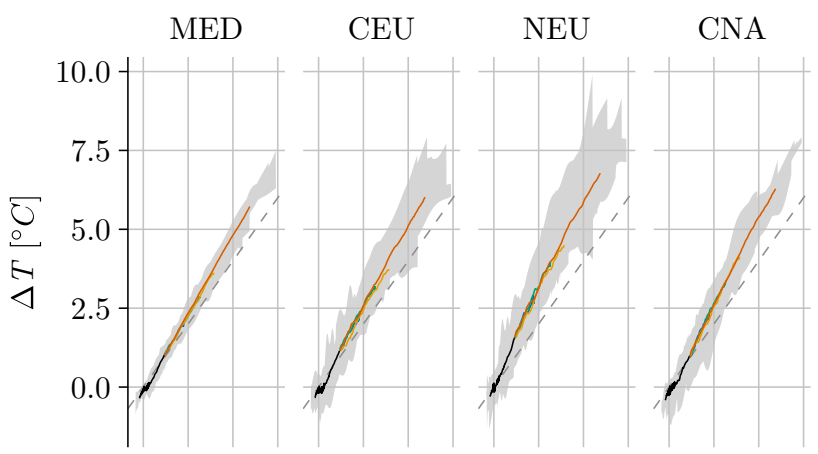

AMZ

EAS
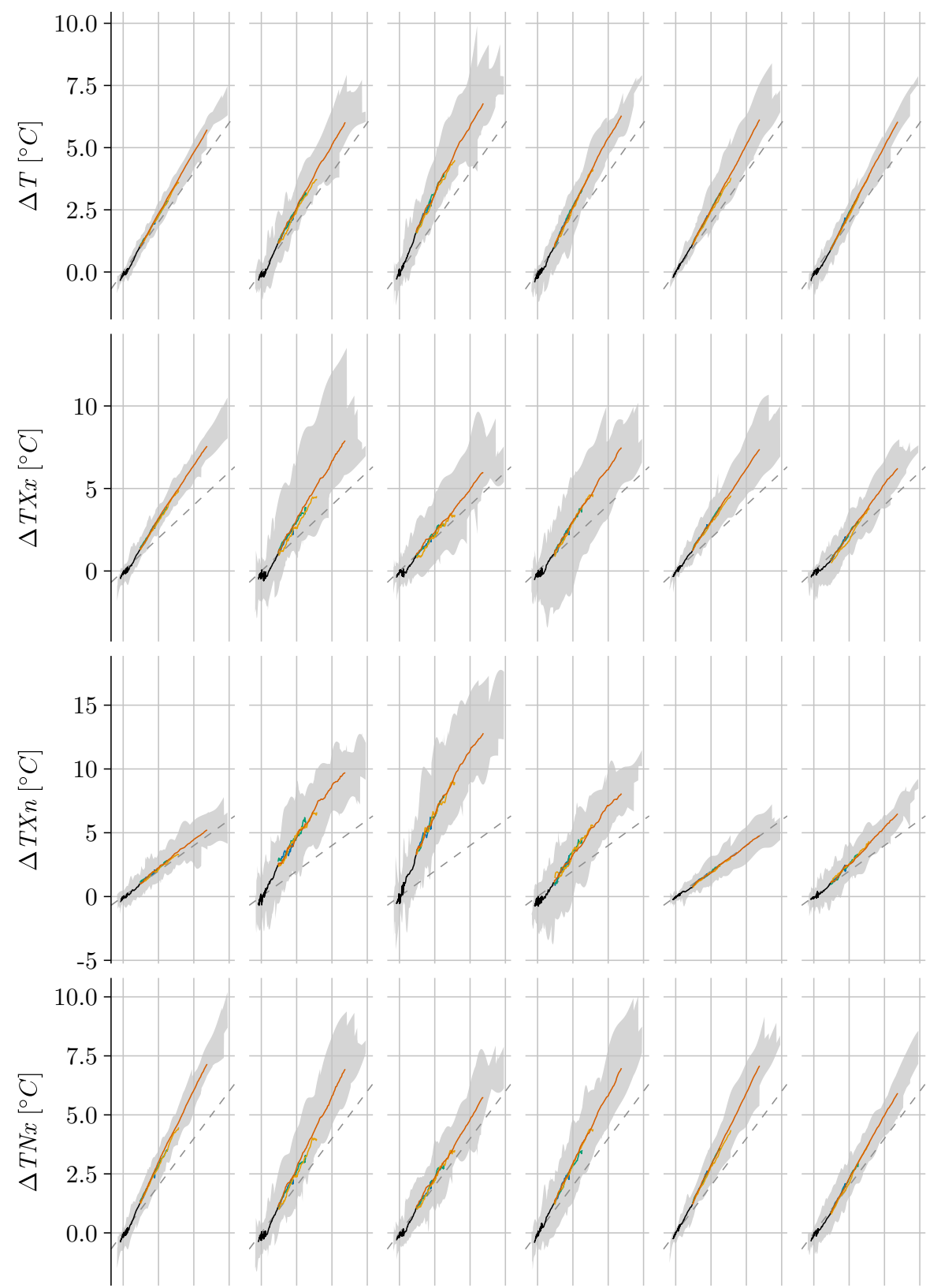

- - Identity line

- Historical

- RCP2.6

- RCP4.5

- RCP6.0

$-\mathrm{RCP} 8.5$

Ensemble spread
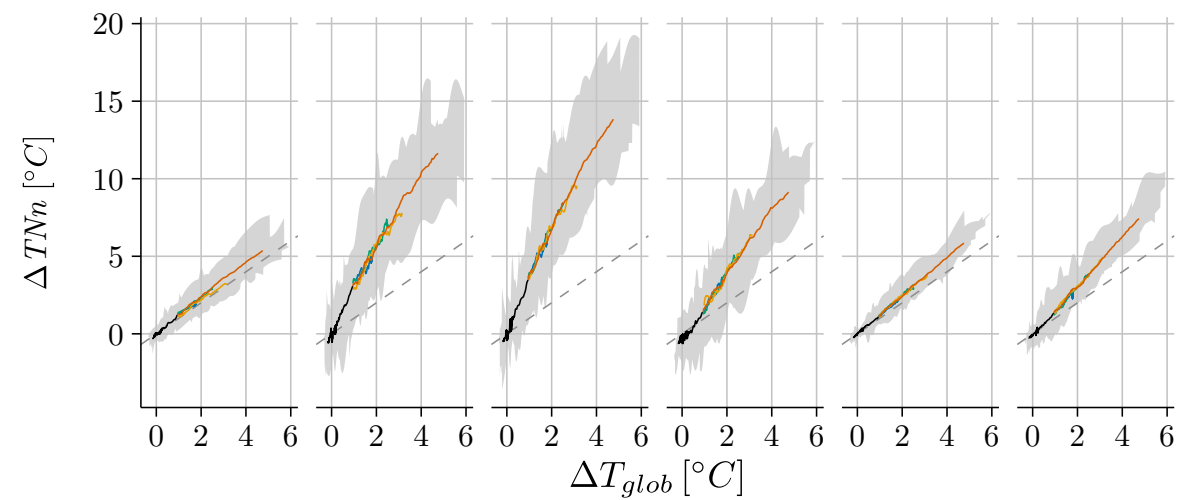

Figure 3. Functional relationships with global mean temperature for the indices $\Delta T, \Delta T_{X x}, \Delta T_{X n}, \Delta T_{N x}$, and $\Delta T_{N n}$, based on CMIP5 simulations of ensemble member r1i1p1 and averaged over the SREX regions MED, CEU, NEU, CNA, AMZ, and EAS. See Table 2 for a description of the indices. 

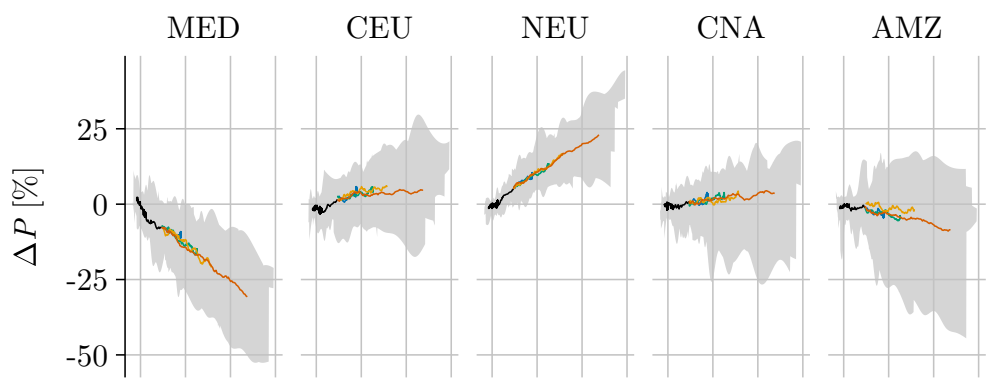

EAS
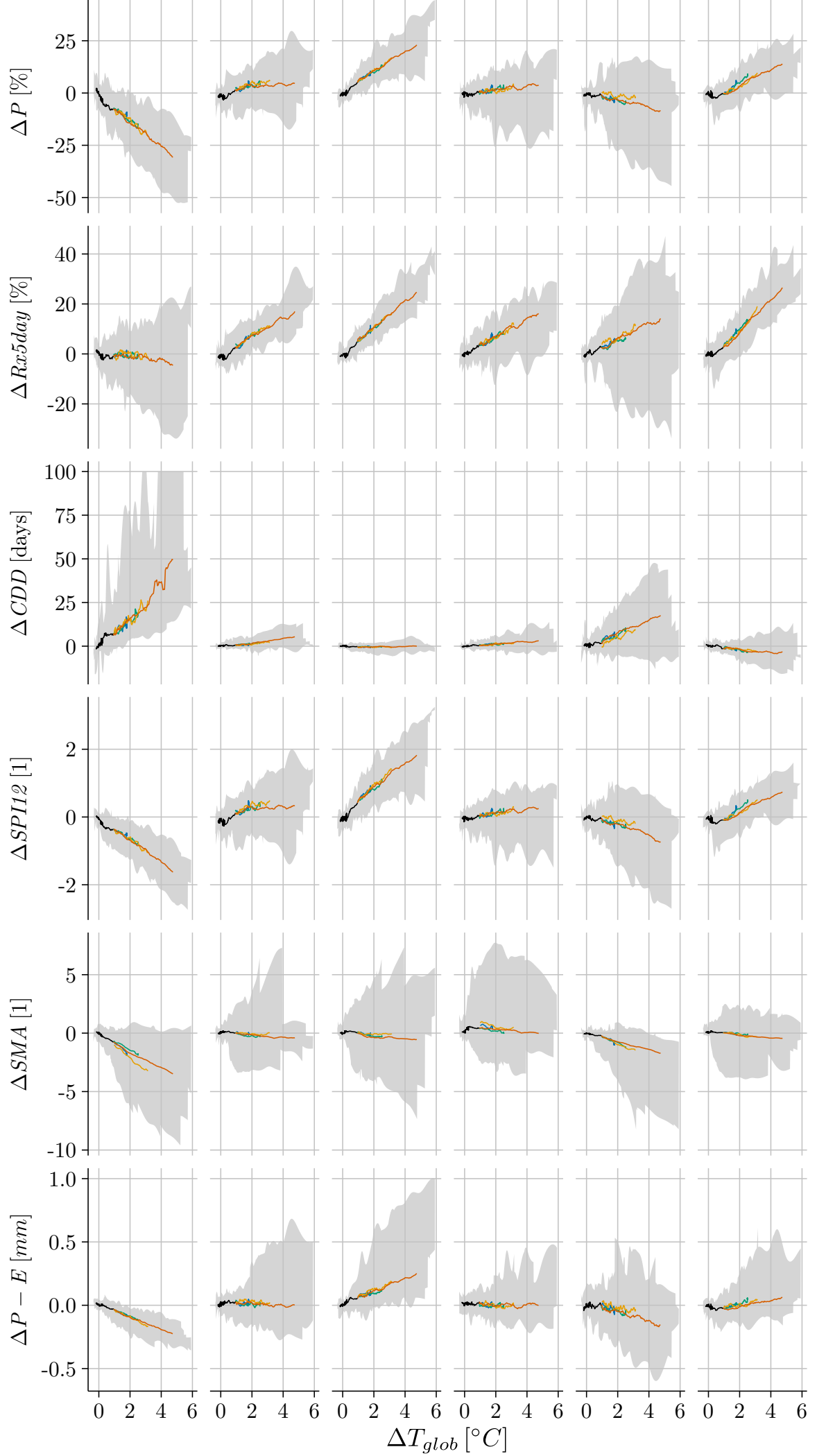

Figure 4. Like Fig. 3 but for the indices $\Delta P, \Delta \mathrm{Rx} 5$ day, $\Delta \mathrm{CDD}, \Delta \mathrm{SPI} 12, \Delta \mathrm{SMA}$, and $\Delta P-E$. Values for $\Delta \mathrm{CDD}>100$ days were cut off for readability. 


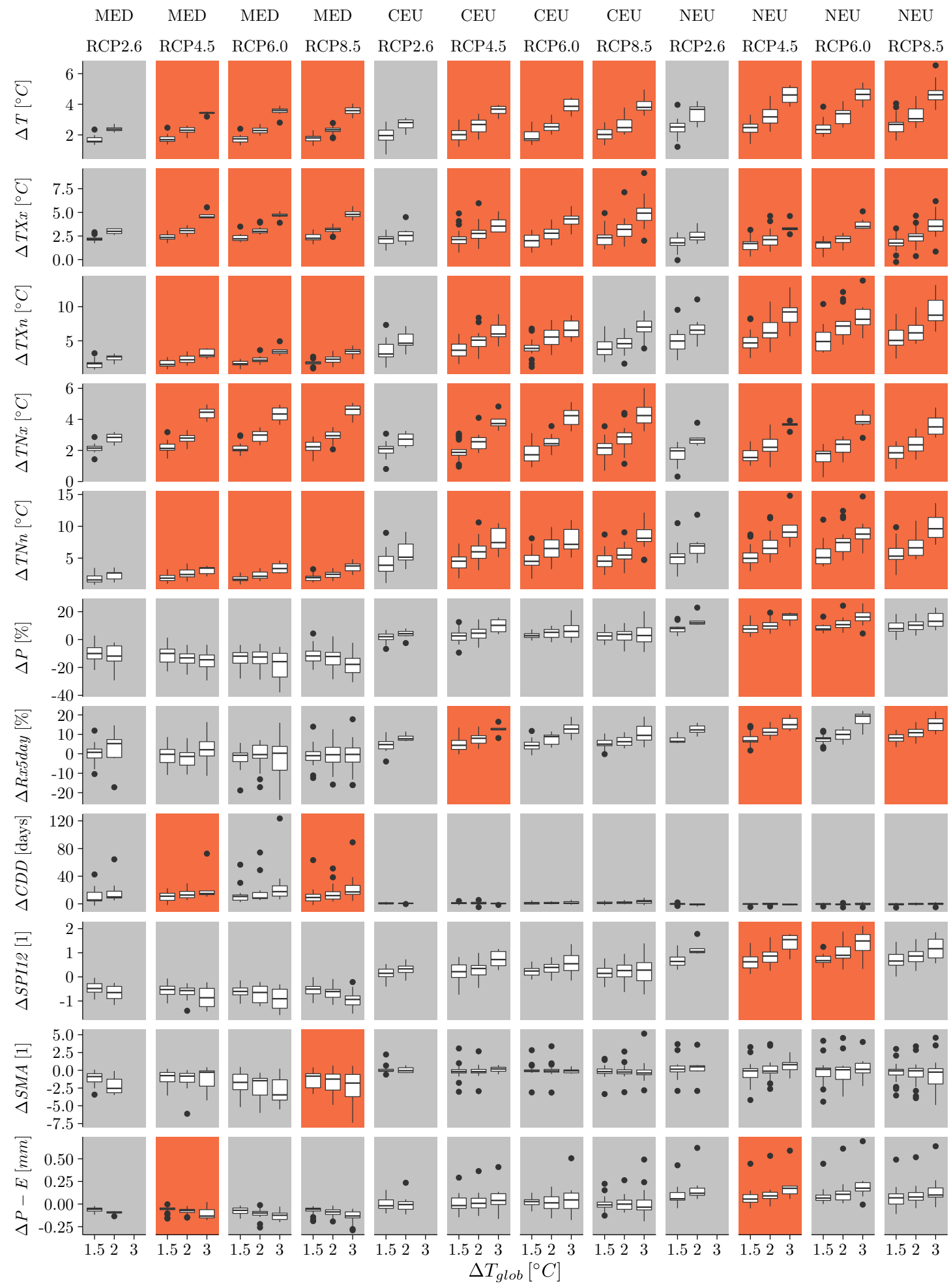

No significant difference in between the distributions of $\Delta I_{\text {reg }}$ for $\Delta T_{\text {glob }}=1.5^{\circ} \mathrm{C}$ and $\Delta T_{\text {glob }}=2{ }^{\circ} \mathrm{C}$

Significant difference in between the distributions of $\Delta I_{\text {reg }}$ for $\Delta T_{\text {glob }}=1.5^{\circ} \mathrm{C}$ and $\Delta T_{\text {glob }}=2{ }^{\circ} \mathrm{C}$

Figure 5. Response of indices $\Delta T, \Delta T_{X x}, \Delta T_{X n}, \Delta T_{N x}, \Delta T_{N n}, \Delta P, \Delta \mathrm{Rx} 5$ day, $\Delta \mathrm{CDD}, \Delta \mathrm{SPI} 12, \Delta \mathrm{SMA}$, and $\Delta P-E$ to a global mean temperature increase of $1.5,2$, and $3{ }^{\circ} \mathrm{C}$ based on CMIP5 simulations of ensemble member r1i1p1 and averaged over the European SREX regions MED, CEU, and NEU. The upper and lower hinges of the box plots represent the first and third quartiles. The whiskers extend to the highest (lowest) value that is within 1.5 times the interquartile range of the upper (lower) hinge. The central line of each box plot indicates the median value. Values outside this range are displayed as dots. 


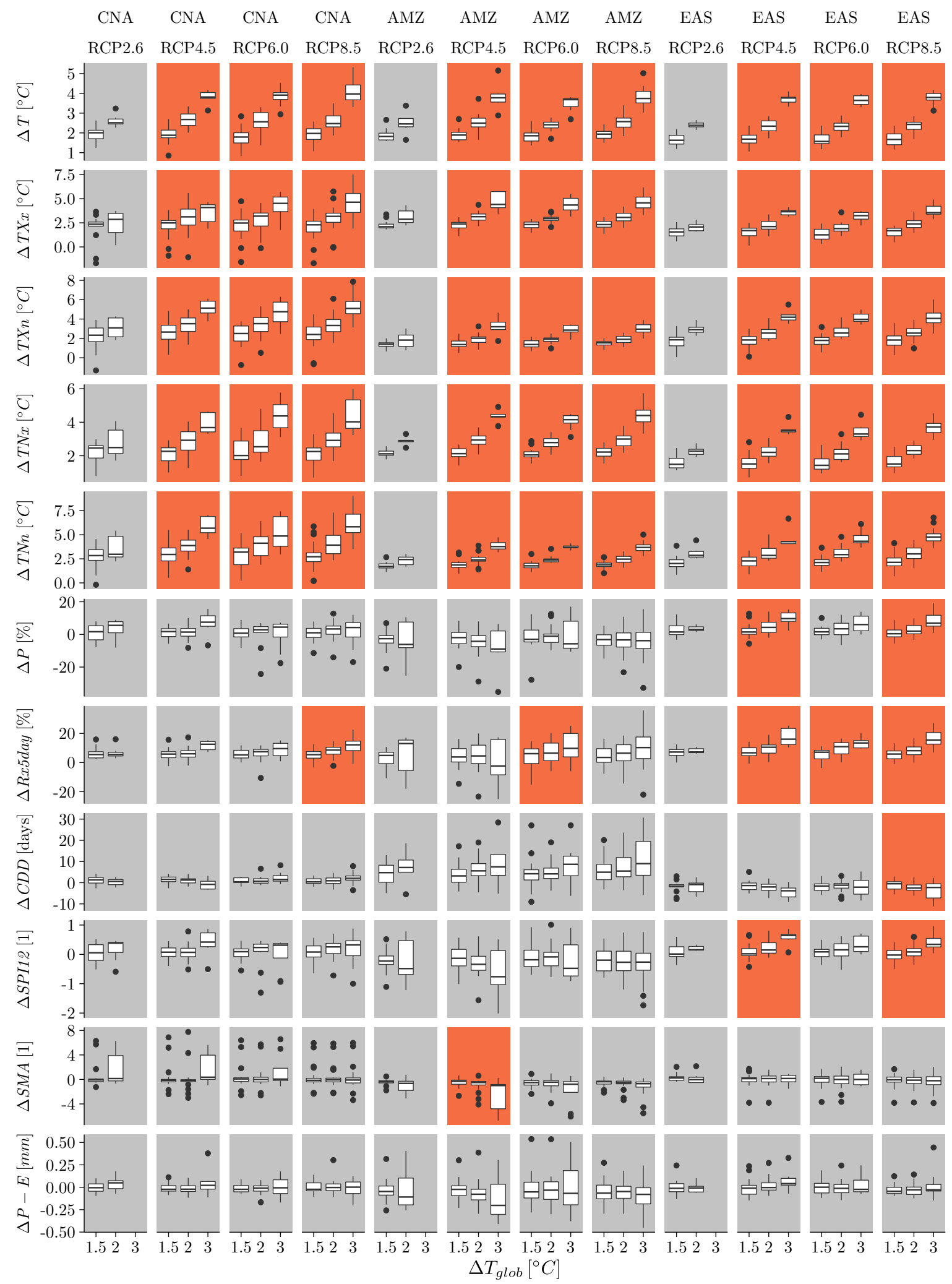

No significant difference in between the distributions of $\Delta I_{\text {reg }}$ for $\Delta T_{\text {glob }}=1.5^{\circ} \mathrm{C}$ and $\Delta T_{\text {glob }}=2{ }^{\circ} \mathrm{C}$ Significant difference in between the distributions of $\Delta I_{\text {reg }}$ for $\Delta T_{\text {glob }}=1.5^{\circ} \mathrm{C}$ and $\Delta T_{\text {glob }}=2{ }^{\circ} \mathrm{C}$

Figure 6. Like Fig. 5 but for SREX regions CNA, AMZ, and EAS. 
Table 3. Scaling slopes of the RCP8.5 scenario for $\Delta T_{\mathrm{glob}} \geq 1{ }^{\circ} \mathrm{C}$ and percent of models with a statistically significant linear scaling (in brackets, $p=0.01$ ) for various SREX regions, based on CMIP5 simulations of ensemble member r1i1p1. Bold values indicate significance for at least $50 \%$ of the contributing models for which the sign of the trend is identical to the sign of the ensemble mean trend. See Table 2 for a description of the indices.

\begin{tabular}{|c|c|c|c|c|c|c|c|c|}
\hline Index & \multicolumn{8}{|c|}{ Regions } \\
\hline$\Delta T / \Delta T_{\mathrm{glob}}\left({ }^{\circ} \mathrm{C}^{\circ} \mathrm{C}^{-1}\right)$ & $1.24(100)$ & $1.26(100)$ & $1.36(100)$ & $1.39(100)$ & $1.30(100)$ & $1.36(100)$ & $\mathbf{0 . 9 6}(100)$ & $1.15(100)$ \\
\hline$\Delta T_{X n} / \Delta T_{\text {glob }}\left({ }^{\circ} \mathrm{C}^{\circ} \mathrm{C}^{-1}\right)$ & $1.11(100)$ & $2.00(100)$ & $2.53(100)$ & $1.86(100)$ & $\mathbf{1 . 0 3}(100)$ & $1.45(100)$ & $\mathbf{0 . 8 5}(100)$ & $\mathbf{0 . 9 2}(100)$ \\
\hline$\Delta T_{N x} / \Delta T_{\text {glob }}\left({ }^{\circ} \mathrm{C}^{\circ} \mathrm{C}^{-1}\right)$ & $\mathbf{1 . 5 5}(100)$ & $1.52(100)$ & $1.21(100)$ & $1.48(100)$ & $1.52(100)$ & $\mathbf{1 . 3 4}(100)$ & $\mathbf{1 . 0 8}(100)$ & $1.24(100)$ \\
\hline$\Delta \mathrm{Rx} 5$ day $/ \Delta T_{\text {glob }}\left(\%{ }^{\circ} \mathrm{C}^{-1}\right)$ & $-0.83(8)$ & $\mathbf{3 . 5 9}(85)$ & $5.10(100)$ & $3.42(77)$ & $3.20(73)$ & $\mathbf{6 . 5 2}(100)$ & $2.10(12)$ & $7.73(85)$ \\
\hline$\Delta \mathrm{CDD} / \Delta T_{\text {glob }}\left(\right.$ days $\left.^{\circ} \mathrm{C}^{-1}\right)$ & $10.73(96)$ & $1.31(50)$ & $0.15(12)$ & $0.68(8)$ & $3.78(62)$ & $-0.91(31)$ & $2.75(58)$ & $-0.93(8)$ \\
\hline$\Delta \mathrm{SPI} 12 / \Delta T_{\text {glob }}\left(1^{\circ} \mathrm{C}^{-1}\right)$ & $-\mathbf{0 . 3 2}(72)$ & $0.05(28)$ & $\mathbf{0 . 3 5}(92)$ & $0.06(20)$ & $-0.15(36)$ & $\mathbf{0 . 2 3}(92)$ & $-0.10(24)$ & $0.22(64)$ \\
\hline$\Delta \mathrm{SMA} / \Delta T_{\text {glob }}\left(1^{\circ} \mathrm{C}^{-1}\right)$ & $-0.62(88)$ & $-0.07(28)$ & $-0.12(28)$ & $-0.13(36)$ & $-\mathbf{0 . 3 6}(52)$ & $-0.10(40)$ & $-0.01(28)$ & $\mathbf{0 . 3 4}(68)$ \\
\hline$\Delta P-E / \Delta T_{\mathrm{glob}}\left(\mathrm{mm}^{\circ} \mathrm{C}^{-1}\right)$ & $\mathbf{- 0 . 0 5}(80)$ & $-0.01(8)$ & $\mathbf{0 . 0 5}(56)$ & $-0.00(0)$ & $-0.04(16)$ & $0.03(32)$ & $-0.01(8)$ & $0.05(40)$ \\
\hline
\end{tabular}

are observable for virtually all of the temperature-based indices, when excluding the RCP2.6 scenario (where only 6 out of 18 models reach $\Delta T_{\text {glob }}=2{ }^{\circ} \mathrm{C}$ ). These findings are mostly independent from the Representative Concentration Pathway (RCP) scenario chosen. For the precipitationbased indices, the differences in the response between the two global mean temperature targets are mostly insignificant. MED is projected to experience the strongest drying, as indicated by the significant increase in $\triangle \mathrm{CDD}$ (RCP4.5 and RCP8.5) and the corresponding decrease in water availability, as reflected by the decrease in $\triangle \mathrm{SMA}$ (RCP8.5) and a decrease in $\Delta P-E$ (RCP4.5), confirming that this region is a potential hotspot for future drought-related changes (Orlowsky and Seneviratne, 2013; Guiot and Cramer, 2016; Schleussner et al., 2016). On the other hand, NEU and EAS (Fig. 6) experience a significant increase in wet extremes. The other non-temperature indices show mostly no statistically significant distinction in the response between the two global mean temperature targets. The large spread in the precipitation-based indices in AMZ indicates that precipitation projections in this region are subject to substantial uncertainties. The number of significant results for the precipitation-based indices shows some dependency on the scenario, with a slight dominance of significant differences in the RCP8.5 scenario.

A broader overview of the significance in differences between 1.5 and $2^{\circ} \mathrm{C}$ global warming (using the same approach as above) considering all ETCCDI indices and SREX regions is provided in Fig. 7. Note that we focus on the RCP8.5 scenario here, as (1) the simulations of this scenario all reach the $2^{\circ}$ global warming level and (2) this scenario constitutes the largest ensemble of simulations (see Fig. A8). There is an obvious dominance in significant differences for virtually all of the temperature related indices except from FD (frost days), GSL (growing season length), and ID (icing days), for which the changes are (nearly) zero in all (sub)tropical regions. Precipitation changes are mostly significant in mid- to high-latitude regions, as reflected by the various related indices. The drought indices ( $P-E$, SMA, and SPI12) show significant changes only in a few regions, either pointing towards a distinct wetting (e.g. SPI12 in east North America ENA) or drying (e.g. SMA in south Africa-SAF).

\subsection{Intra-model variability}

The functional relationships and uncertainty ranges discussed so far are based on one ensemble member (r1ilp1) of the applied models (see Table 1). In order to investigate any impact of intra-model variability on this range, Fig. 8 displays the ensemble mean and uncertainty ranges based on all ensemble members available for each model vs. the one-member-based ensemble mean and uncertainty range on the example of the precipitation-based indices discussed earlier. The regional signal of the functional relationship of $\triangle$ SMA based on all ensemble members of the RCP4.5 scenario shows some inconsistencies with the other scenarios, which was found to be due to biases in one individual model simulation. Apart from this, the consideration of all members (and thus intra-model variability) results in a marginally enhanced uncertainty range (the largest enhancements were found for $\triangle \mathrm{CDD}$ and $\triangle \mathrm{SMA}$ ), while the ensemble mean is nearly identical to the ensemble mean of the one-memberbased indices. Thus, the uncertainty ranges based on one member seem to be appropriate to also cover intra-model variability. However, a number of models provide only the r1ilp1 simulation, potentially resulting in an underestimation of the true inter-model variability. Moreover, including only one run per model avoids models which provide more runs having a higher weight in the ensemble results. 


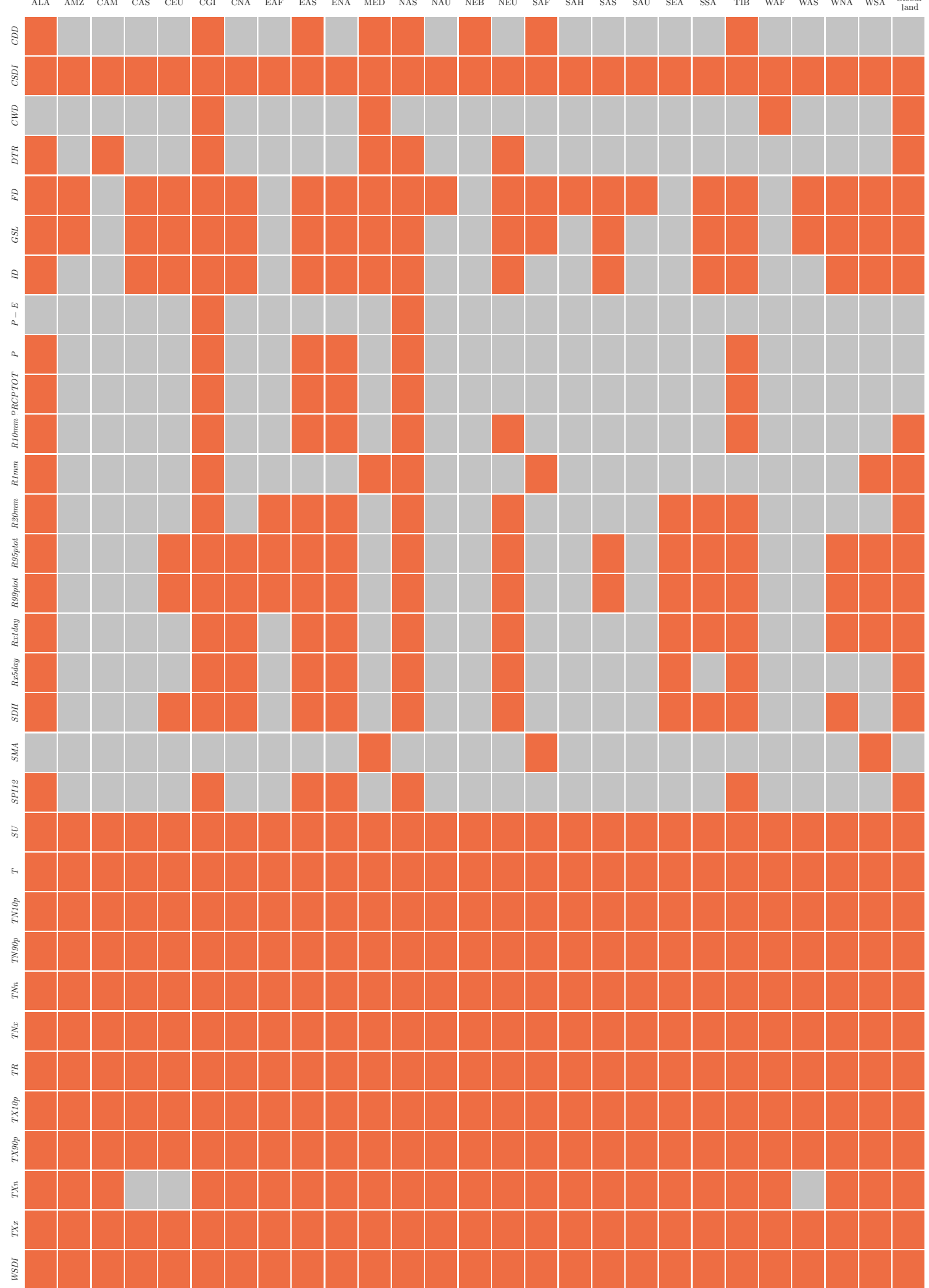

No significant difference in between the distributions of $\Delta I_{\text {reg }}$ for $\Delta T_{g l o b}=1.5^{\circ} \mathrm{C}$ and $\Delta T_{g l o b}=2^{\circ} \mathrm{C}$

Significant difference in between the distributions of $\Delta I_{\text {reg }}$ for $\Delta T_{g l o b}=1.5^{\circ} \mathrm{C}$ and $\Delta T_{g l o b}=2^{\circ} \mathrm{C}$

Figure 7. Significance of differences of $\Delta I_{\text {reg }}$ in between the 1.5 and $2{ }^{\circ} \mathrm{C}$ global mean temperature targets based on mean temperature $T$, mean precipitation $P$, the drought indices defined in Sect. 2.2, and all ETCCDI indices as defined in Sillmann et al. (2013a) (rows). Columns indicate SREX regions (according to IPCC AR5; http://www.ipcc-data.org/guidelines/pages/ar5_regions.html) and global land. 


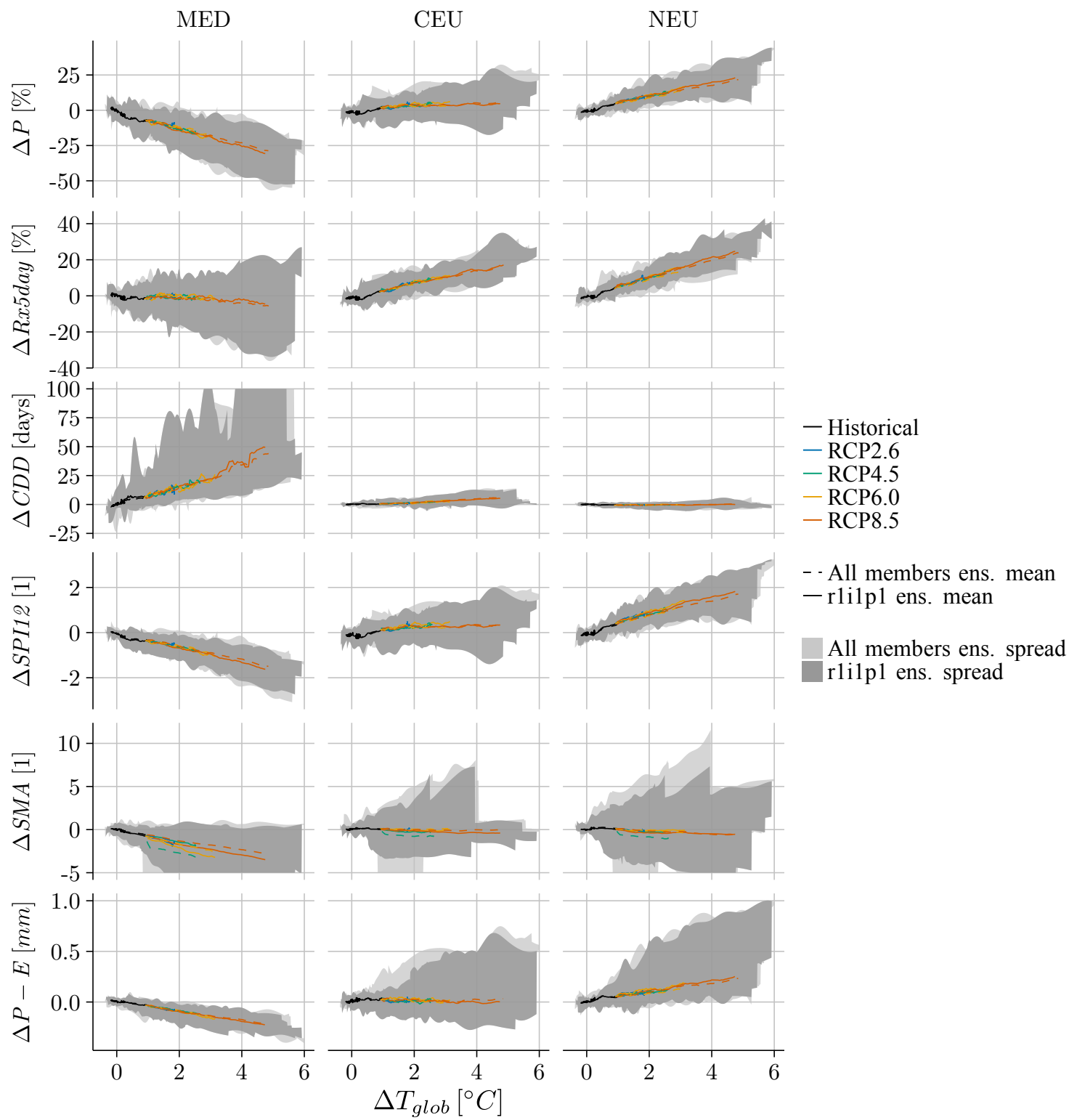

Figure 8. Functional relationships with global mean temperature for the indices $\Delta P, \Delta \mathrm{Rx} 5$ day, $\Delta \mathrm{CDD}, \Delta \mathrm{SPI} 12, \Delta \mathrm{SMA}$, and $\Delta P-E$, averaged over the SREX regions MED, CEU, and NEU. Indices based on all CMIP5 ensemble members available per model (solid lines, dark shading) are compared with indices based on ensemble member r1i1p1 of each model (dashed lines, light shading). Values for $\Delta \mathrm{CDD}>$ 100 days and $\triangle \mathrm{SMA}<-5$ were cut off for readability.

\subsection{Beyond 2100}

While most CMIP5 model simulations end by the end of the 21 st century, a few simulations are available up to the year 2299 (see Table 1). These allow us to analyse the functional relationship beyond 2100 and to assess their longer-term behaviour.

The long-term functional relationship of changes in temperature-related indices to changes in global mean temperature is similar (i.e. mostly linear in the ensemble mean) to the one shown in Fig. 3 (not shown). For the other indices, the linear scaling assumption for the 1861-2299 period apparently only holds for a subset of indices and differs among regions (Fig. 9). Regions in which the indices scale linearly with $\Delta T_{\text {glob }}$ in the RCP8.5 scenario are also often characterized by a near-linear response in the other scenarios, which is remarkable given the fact that $\Delta T_{\text {glob }}$ is projected to remain constant or to decrease over time in these scenarios. In the RCP8.5 scenario, the trend towards more extreme dry conditions in MED (and partly in AMZ) is projected to continue also beyond 2100, while NEU and EAS are characterized by a continuation of the intensification in wet extremes on both 

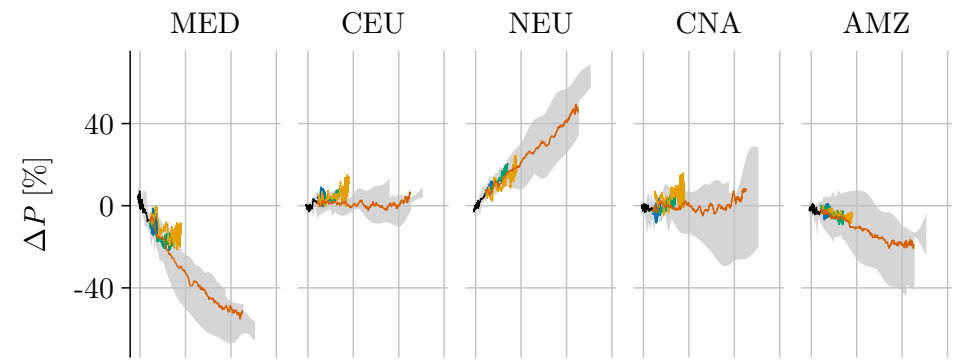

EAS
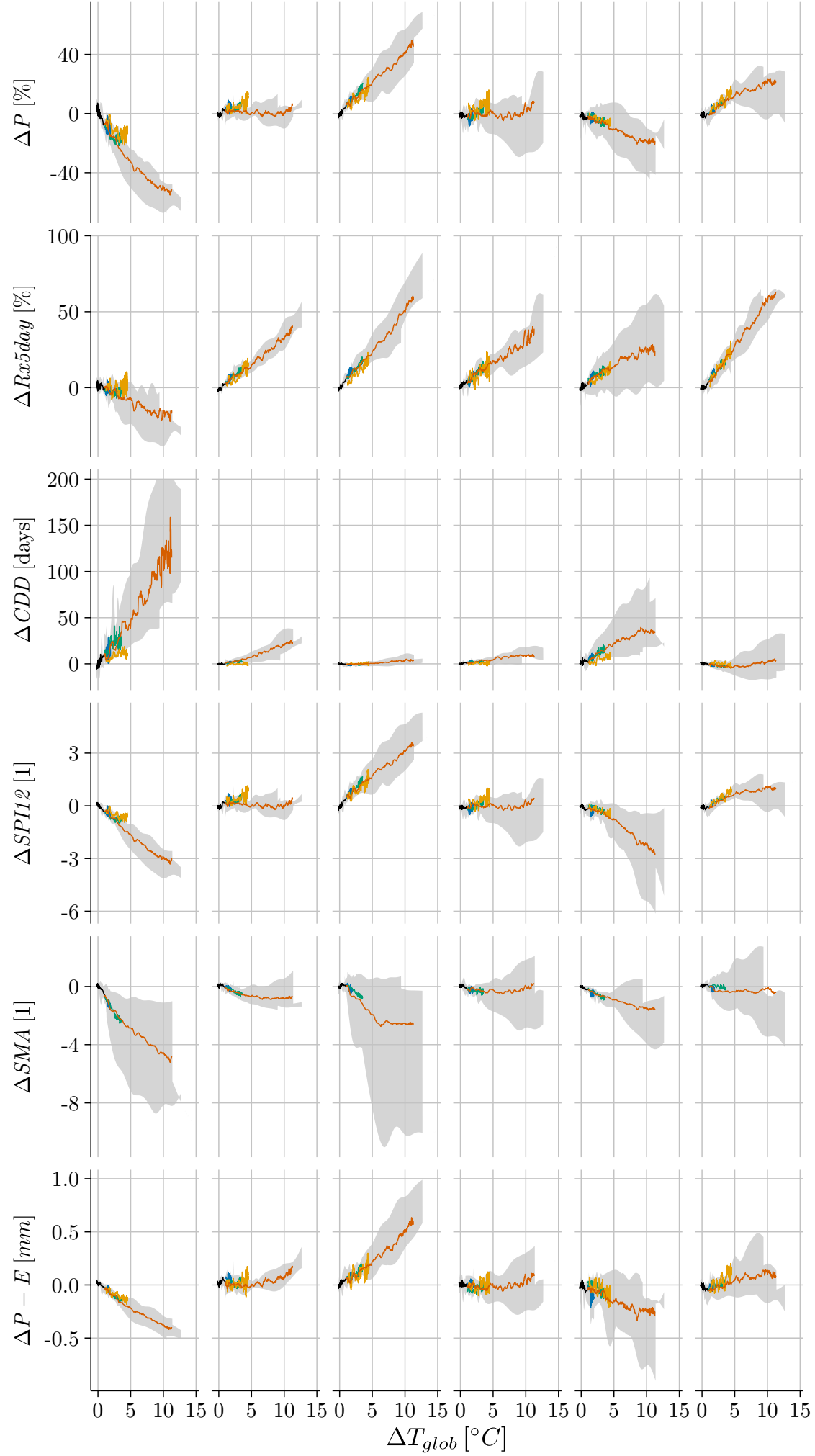

Figure 9. Like Fig. 4 but for the time period 1861-2299. Values for $\Delta C D D>200$ days were cut off for readability. 
short ( $\Delta \mathrm{Rx} 5$ day $)$ and longer-term $(\Delta \mathrm{SPI} 12)$ timescales. Irrespective of the changes in $\Delta P, \Delta \mathrm{Rx} 5$ day continues to increase in a near-linear fashion in all regions except MED.

\section{Conclusions}

We have developed the "DROUGHT-HEAT Regional Climate Atlas", a new interactive web interface available via http://www.drought-heat.ethz.ch/atlas, which provides plots of the functional relationship between changes in regional climate indices and global mean temperature for 26 larger IPCC predefined regions. Besides acting as a platform to foster scientific discussion, the aim of this web interface is to increase the accessibility of peer-reviewed scientific results to the general public, which is of major concern for the communication of climate science findings (e.g. Harold et al., 2016). This is particularly relevant for the critical evaluation of the regional-scale implications of considered global mean temperature limits, such as the 1.5 and $2{ }^{\circ} \mathrm{C}$ temperature goals established in the 2015 Paris Agreement.

With the selected results presented here, we have demonstrated that a number of regionally averaged climate indices show a distinct linear relationship with global mean temperatures both in the ensemble mean and in individual CMIP5 model realizations, as also illustrated in S16 for a more limited set of indices and emissions scenarios. The linear relationship is particularly obvious for the analysed temperaturederived indices and still present for a number of drought and water-cycle indices. We note, however, that some analyses display departures from such linear relationships, in particular in the case of indices showing a low signal to noise in projections (e.g. in several regions for mean precipitation, dry spell lengths, soil moisture anomalies, and precipitation minus evapotranspiration). Such departures are generally more pronounced in the RCP2.6 scenario, because of the weak overall forcing in that emission scenario, and possibly also because of differences in aerosol forcing in RCP2.6 compared to the other emission scenarios (Pendergrass et al., 2015). These cases of non linearities illustrate the advantage of the applied S16 approach compared to traditional pattern scaling approaches, as the derived functional relationships are purely empirical and not assessed from a priori determined mathematical relationships.
Projected changes in the indices are overall larger in a $2^{\circ} \mathrm{C}$ world (i.e. $\Delta T_{\text {glob }}=2{ }^{\circ} \mathrm{C}$ relative to pre-industrial levels) compared to a $1.5^{\circ} \mathrm{C}$ world (i.e. $\Delta T_{\text {glob }}=1.5^{\circ} \mathrm{C}$ relative to pre-industrial levels). The differences between the two global mean temperature limits are particularly large and generally significant for regional mean and extreme temperatures. Results tend to be less robust for water-cycle indices, in particular for those related to water availability (soil moisture anomalies or precipitation minus evapotranspiration). We encourage the reader to use the DROUGHT-HEAT Regional Climate Atlas to evaluate these regional functional relationships using other indices or other regions than those presented in this study.

The DROUGHT-HEAT Regional Climate Atlas has been designed to be easily expanded both in terms of functionality (e.g. adding support for additional plot types) and in terms of the number and type of supported data sets and diagnostics. By these means, we facilitate an easy extension of the platform to include graphical material from upcoming publications within the scope of the DROUGHT-HEAT project and beyond.

Code availability. All code used to prepare the results discussed within this study is available upon request from the first author.

Data availability. All data produced within this study are available via the website http://drought-heat.ethz.ch/atlas/ through the export functions of the plots (not including individual ensemble members). Raw data are available upon request from the first author. 


\section{Appendix A: Supplementary figures}

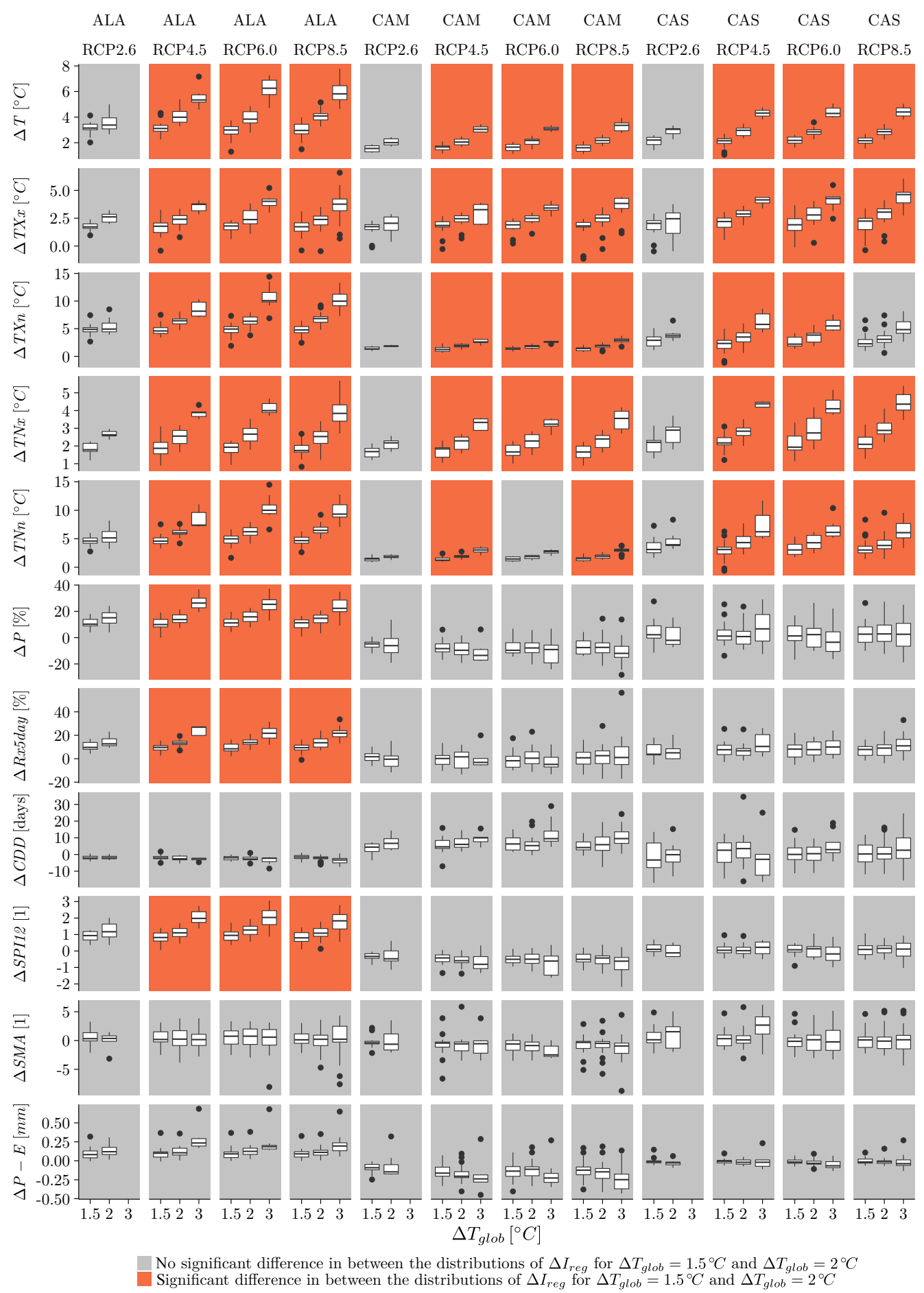

Figure A1. Response of indices $\Delta T, \Delta T_{X x}, \Delta T_{X n}, \Delta T_{N x}, \Delta T_{N n}, \Delta P, \Delta \mathrm{Rx} 5$ day, $\Delta \mathrm{CDD}, \Delta \mathrm{SPI} 12, \Delta \mathrm{SMA}$, and $\Delta P-E$ to global mean temperature increases of $1.5,2$, and $3{ }^{\circ} \mathrm{C}$ based on CMIP5 simulations of ensemble member r1ilp1 and averaged over the SREX regions ALA, CAM, and CAS. The upper and lower hinges of the box plots represent the first and third quartiles. The whiskers extend to the highest (lowest) value that is within 1.5 times the interquartile range of the upper (lower) hinge. The central line of each box plot indicates the median value. Values outside this range are displayed as dots. See Table 2 for a description of the indices. 


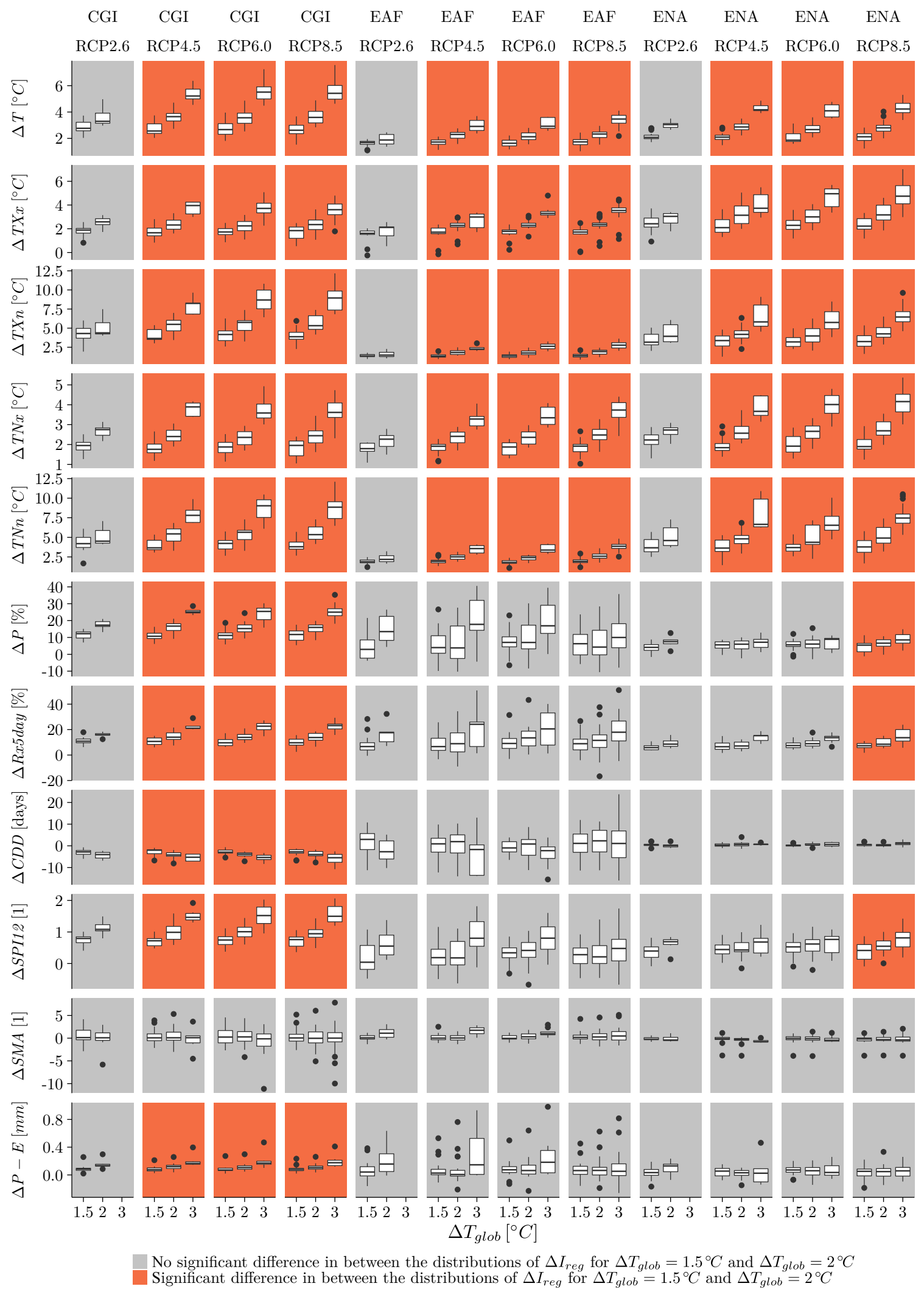

Figure A2. Like Fig. A1 but for SREX regions CGI, EAF, and ENA. 


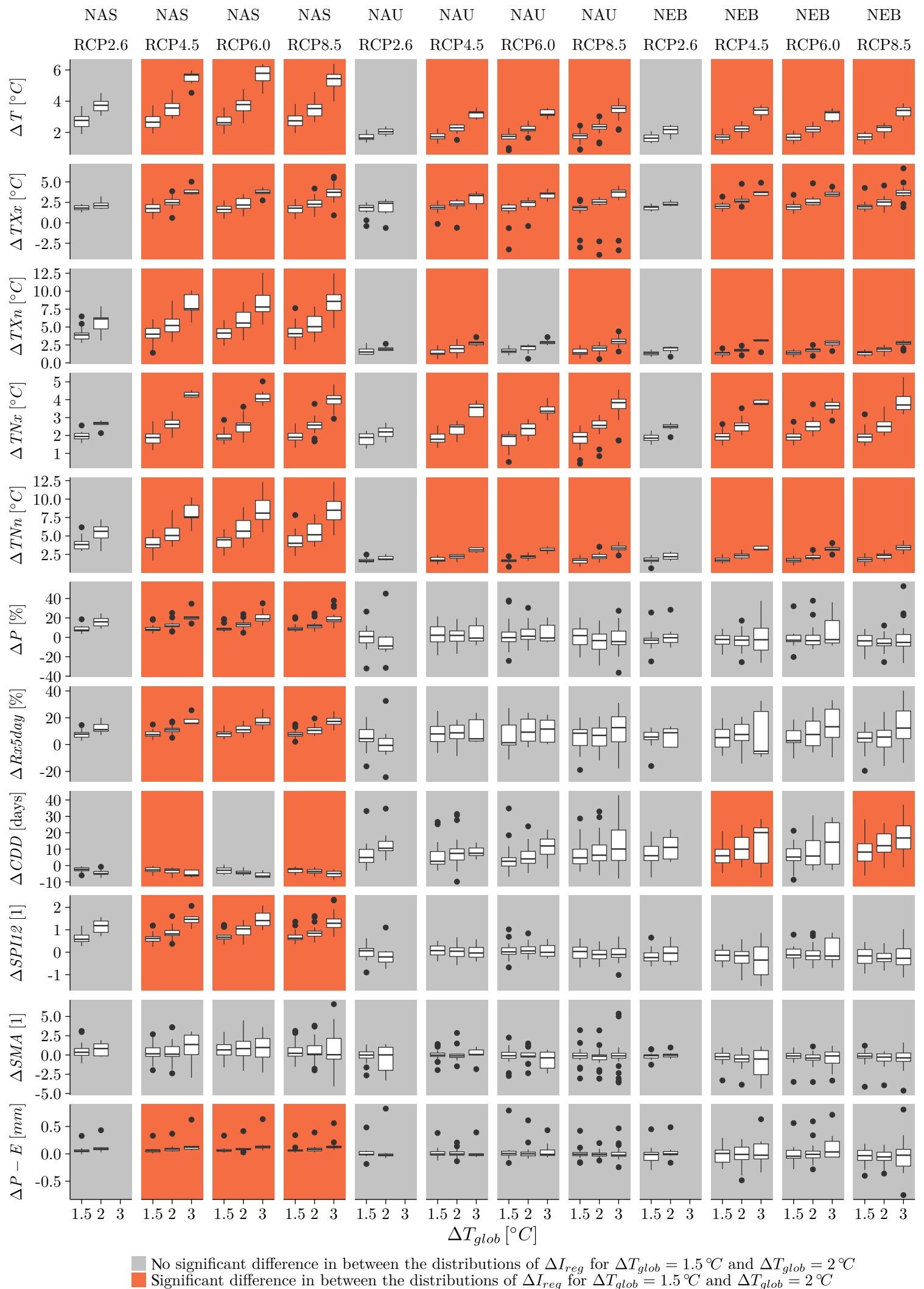

Figure A3. Like Fig. A1 but for SREX regions NAS, NAU, and NEB. 


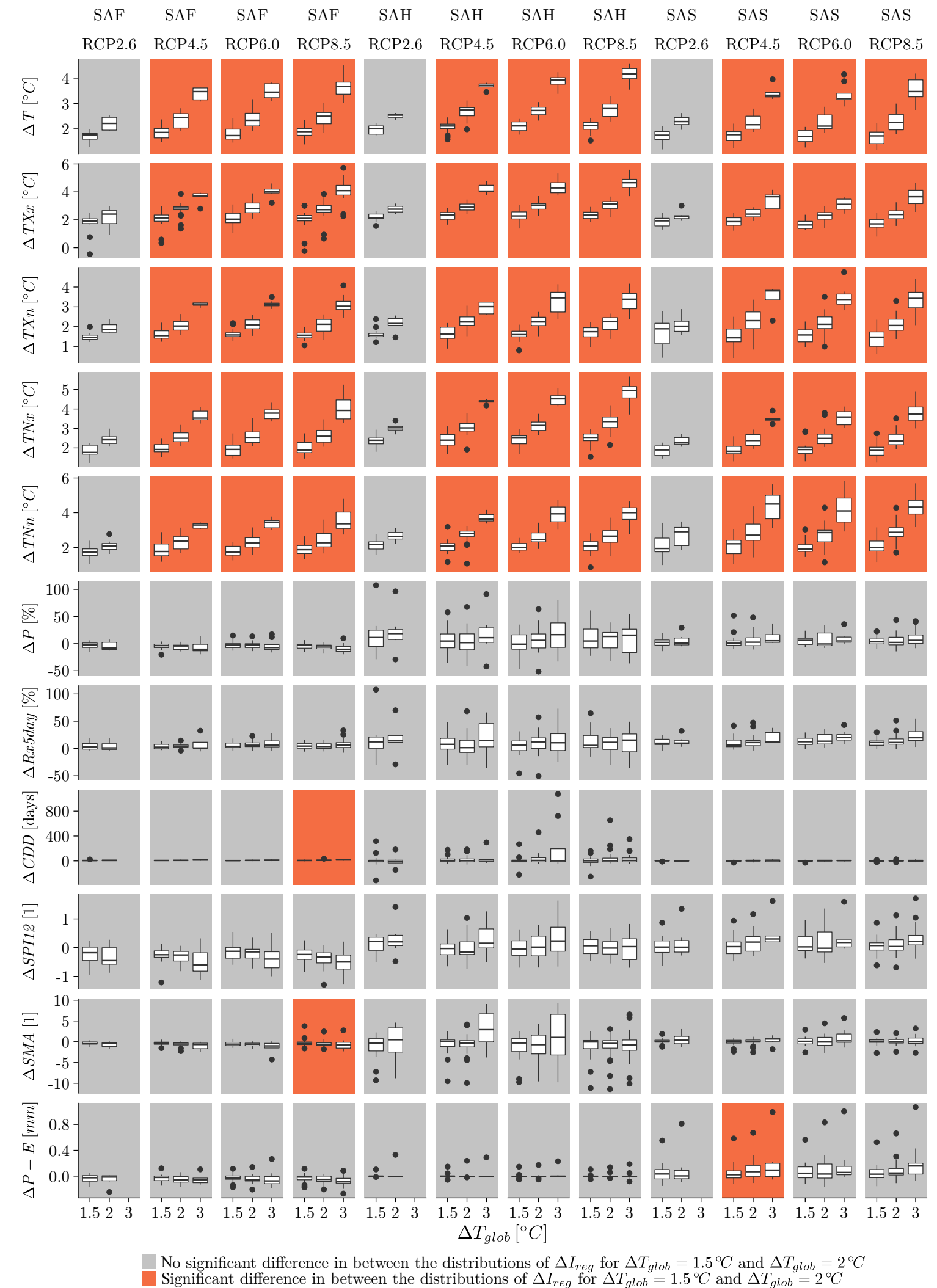

Figure A4. Like Fig. A1 but for SREX regions SAF, SAH, and SAS. 


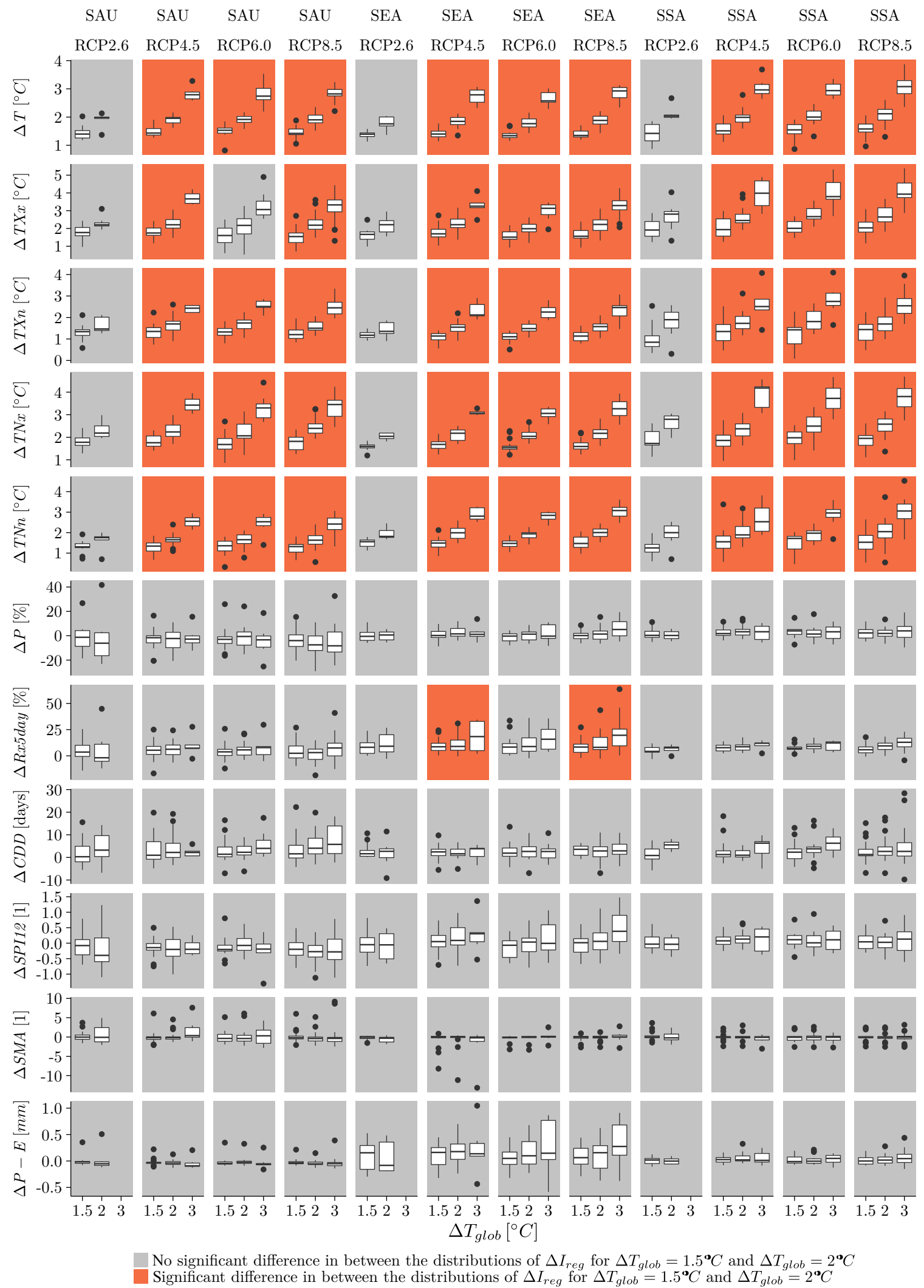

Figure A5. Like Fig. A1 but for SREX regions SAU, SEA, and SSA. 
TIB TIB TIB TIB WAF WAF WAF WAF WAS WAS WAS WAS

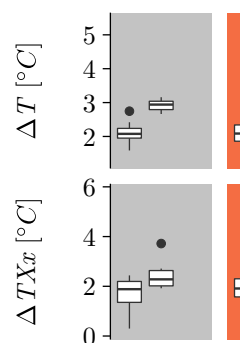

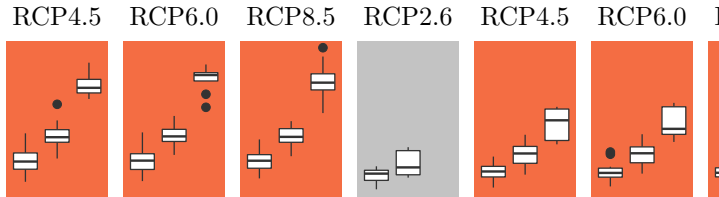

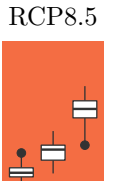
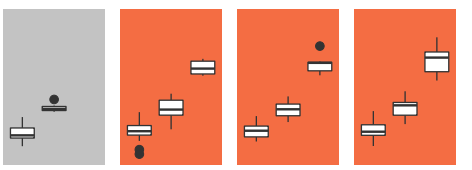

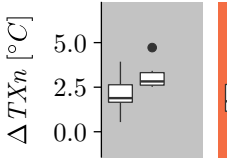
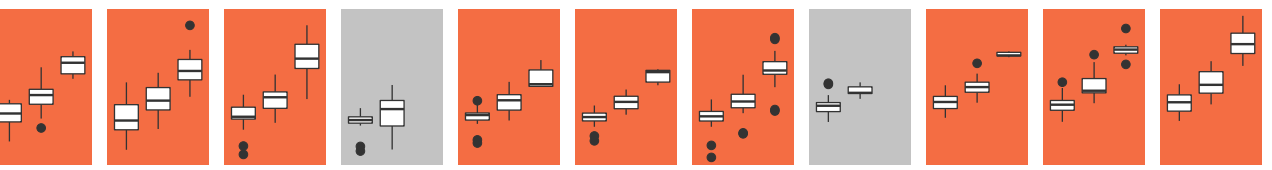

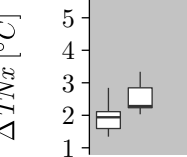
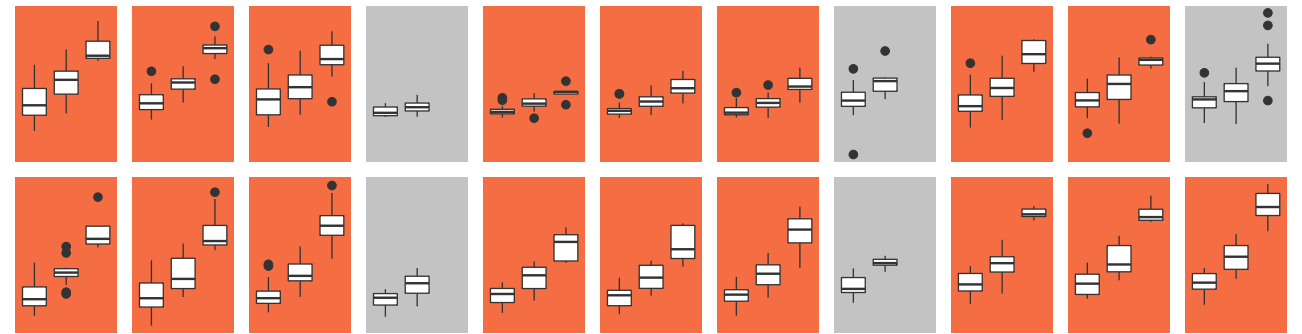

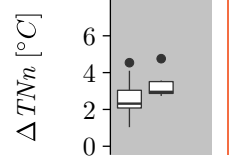
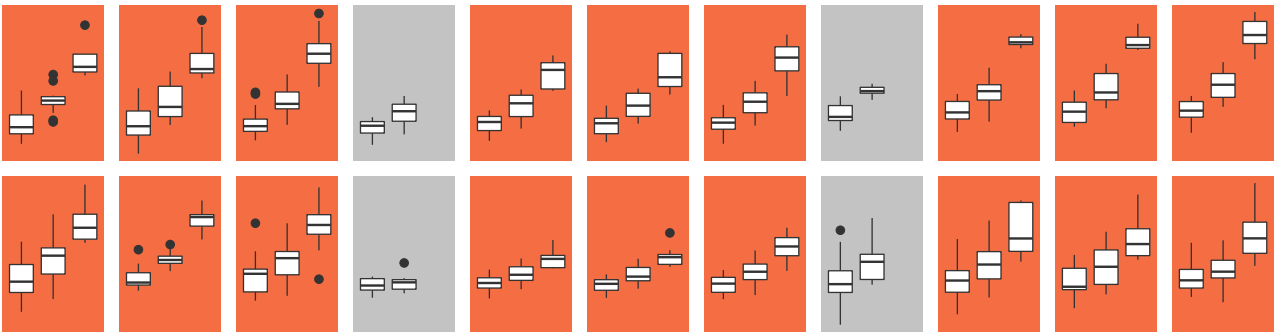

$\begin{array}{rr}\frac{5}{8} & 60 \\ 8 & 0 \\ 8 & -30\end{array}-$ 审官
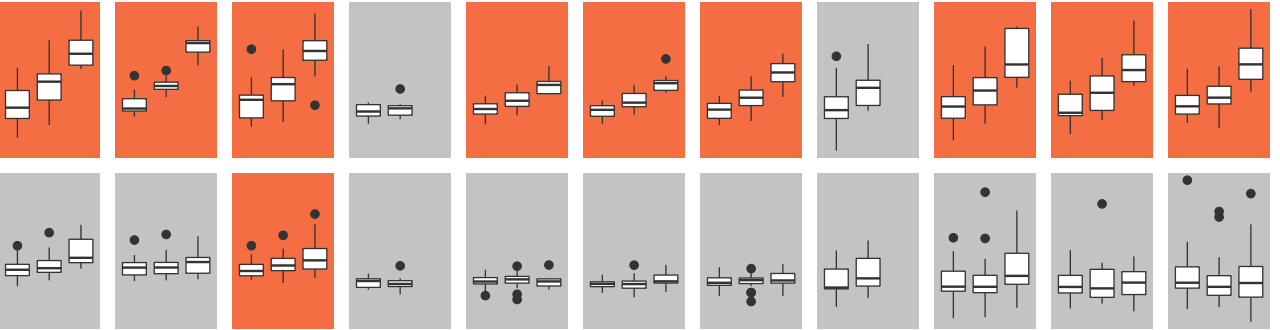

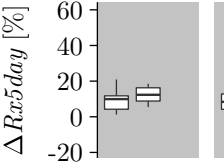
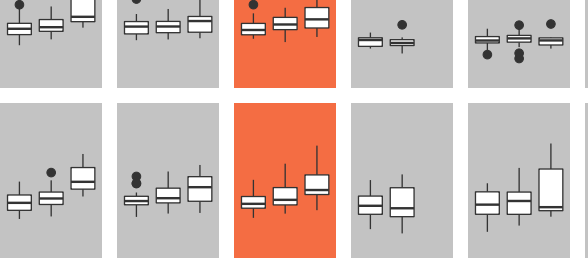

$+\stackrel{\text { +ு }}{+}$
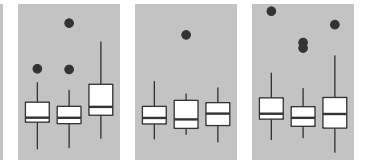

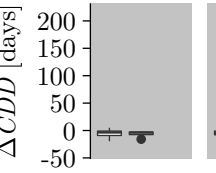
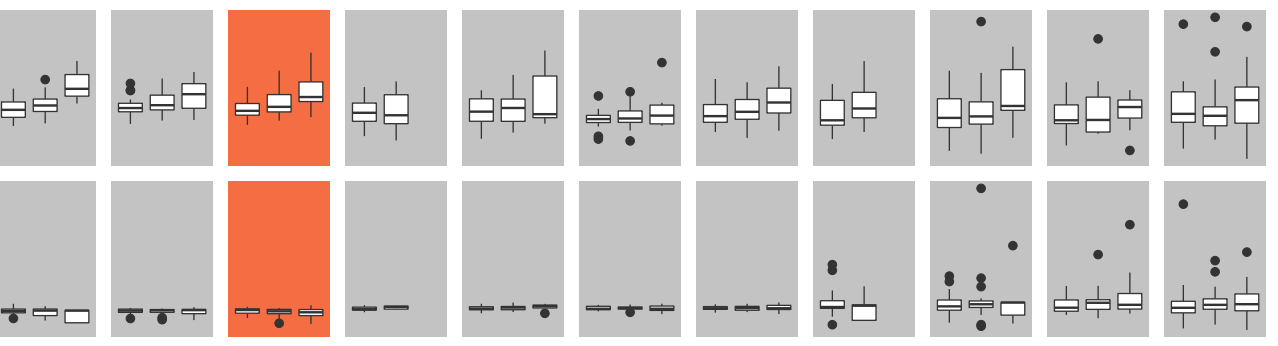

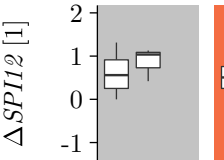
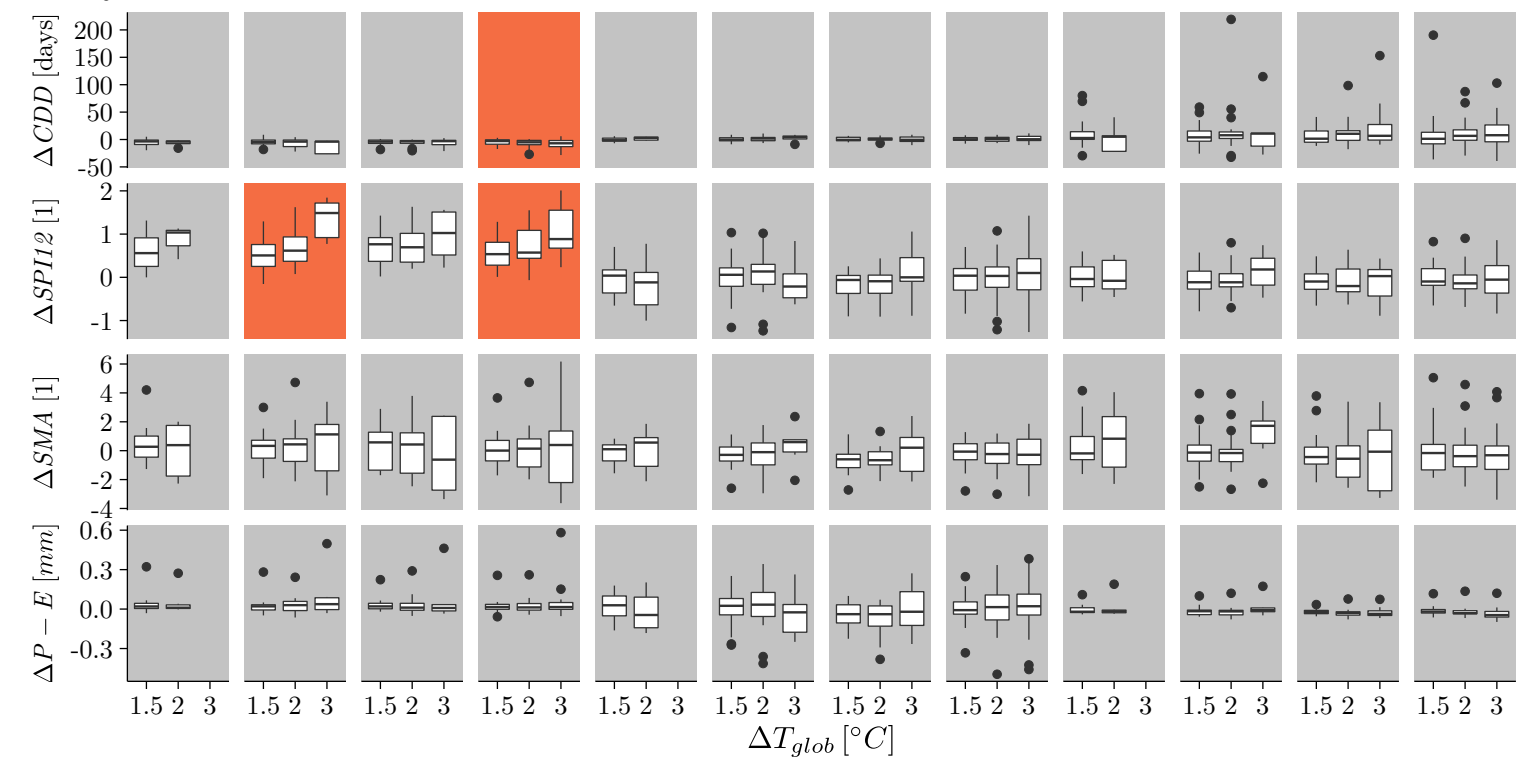

No significant difference in between the distributions of $\Delta I_{\text {reg }}$ for $\Delta T_{\text {glob }}=1.5^{\circ} \mathrm{C}$ and $\Delta T_{\text {glob }}=2{ }^{\circ} \mathrm{C}$ Significant difference in between the distributions of $\Delta I_{\text {reg }}$ for $\Delta T_{\text {glob }}=1.5^{\circ} \mathrm{C}$ and $\Delta T_{\text {glob }}=2{ }^{\circ} \mathrm{C}$

Figure A6. Like Fig. A1 but for SREX regions TIB, WAF, and WAS. 


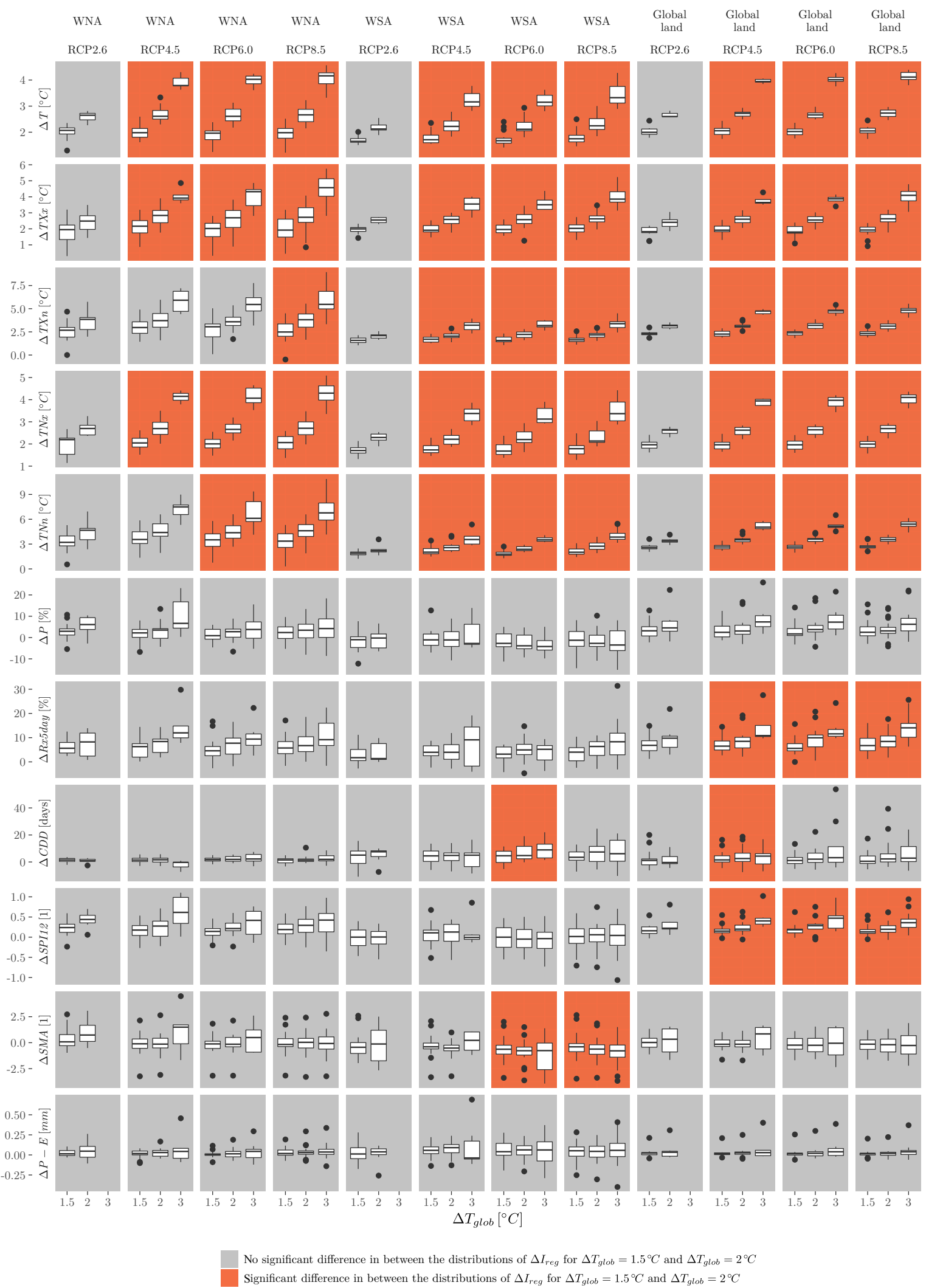

Figure A7. Like Fig. A1 but for SREX regions WNA and WSA, and for global land. 


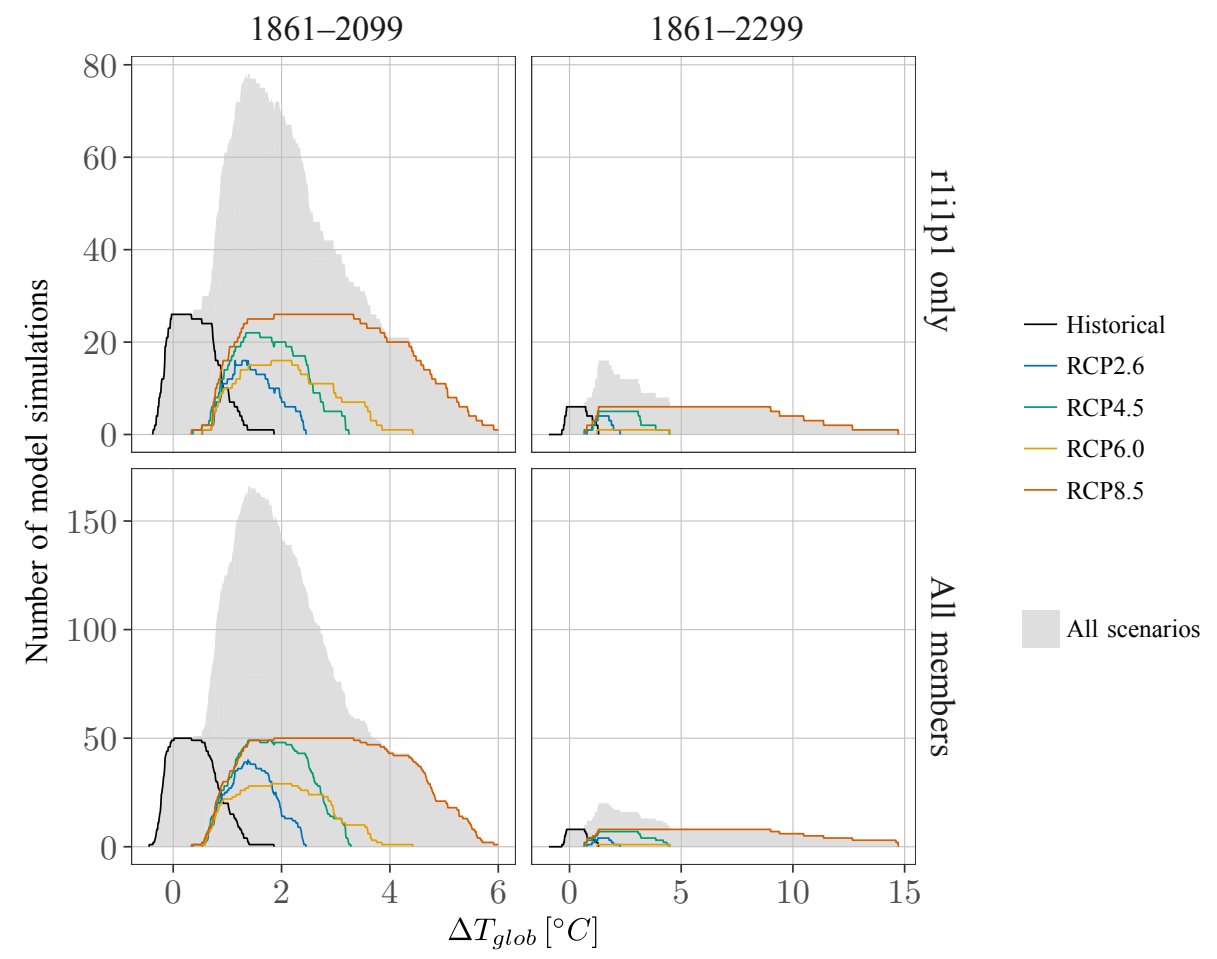

Figure A8. Number of models simulating a specific global mean temperature ( $x$ axis) per scenario (coloured lines) and for all scenarios combined (grey shading), subdivided by the time period covered (columns) and by the number of ensemble members used (rows). The number of data points shown in each subplot is the same for each region and index except from $\Delta P-E$, where we do not use simulations from CMCC-CMS, as evaporation is not available from this model (see Table 1). 
Competing interests. The authors declare that they have no conflict of interest.

Acknowledgements. R. Wartenburger and S. I. Seneviratne acknowledge the European Research Council (ERC) "DROUGHTHEAT" project funded by the European Community's Seventh Framework Programme (grant agreement FP7-IDEAS-ERC617518). This study contributes to the World Climate Research Programme (WCRP) Grand Challenge on Extremes. We acknowledge the World Climate Research Programme's Working Group on Coupled Modelling, which is responsible for CMIP, and we thank the climate modelling groups (listed in Table 1 of this paper) for producing and making available their model output. For CMIP, the US Department of Energy's Program for Climate Model Diagnosis and Intercomparison provides coordinating support and led development of software infrastructure in partnership with the Global Organization for Earth System Science Portals.

Edited by: Richard Neale

Reviewed by: Ben Sanderson and one anonymous referee

\section{References}

Benjamini, Y. and Hochberg, Y.: Controlling the false discovery rate: a practical and powerful approach to multiple testing, J. R. Stat. Soc., 57, 289-300, 1995.

Cowtan, K., Hausfather, Z., Hawkins, E., Jacobs, P., Mann, M. E., Miller, S. K., Steinman, B. A., Stolpe, M. B., and Way, R. G.: Robust comparison of climate models with observations using blended land air and ocean sea surface temperatures, Geophys. Res. Lett., 42, 2015GL064888, https://doi.org/10.1002/2015GL064888, 2015.

Fischer, E. M. and Knutti, R.: Anthropogenic contribution to global occurrence of heavy-precipitation and hightemperature extremes, Nat. Clim. Change, 5, 560-564, https://doi.org/10.1038/nclimate2617, 2015.

Fischer, E. M., Sedlacek, J., Hawkins, E., and Knutti, R.: Models agree on forced response pattern of precipitation and temperature extremes, Geophys. Res. Lett., 41, 2014GL062018, https://doi.org/10.1002/2014GL062018, 2014.

Frieler, K., Meinshausen, M., Mengel, M., Braun, N., and Hare, W.: A scaling approach to probabilistic assessment of regional climate change, J. Climate, 25, 3117-3144, https://doi.org/10.1175/JCLI-D-11-00199.1, 2012.

Greve, P. and Seneviratne, S. I.: Assessment of future changes in water availability and aridity, Geophys. Res. Lett., 42, 54935499, https://doi.org/10.1002/2015GL064127, 2015.

Guiot, J. and Cramer, W.: Climate change: The 2015 Paris Agreement thresholds and Mediterranean basin ecosystems, Science, 354, 465-468, https://doi.org/10.1126/science.aah5015, 2016.

Harold, J., Lorenzoni, I., Shipley, T. F., and Coventry, K. R.: Cognitive and psychological science insights to improve climate change data visualization, Nat. Clim. Change, 6, 1080-1089, https://doi.org/10.1038/nclimate3162, 2016.

Huntingford, C. and Cox, P. M.: An analogue model to derive additional climate change scenarios from ex- isting GCM simulations, Clim. Dynam., 16, 575-586, https://doi.org/10.1007/s003820000067, 2000.

James, R., Washington, R., Schleussner, C.-F., Rogelj, J., and Conway, D.: Characterizing half-a-degree difference: a review of methods for identifying regional climate responses to global warming targets, WIRES Clim. Change, 8, e457, https://doi.org/10.1002/wcc.457, 2017.

Knutti, R., Rogelj, J., Sedlacek, J., and Fischer, E. M.: A scientific critique of the two-degree climate change target, Nat. Geosci., 9, 13-18, https://doi.org/10.1038/ngeo2595, 2016.

Kravitz, B., Lynch, C., Hartin, C., and Bond-Lamberty, B.: Exploring precipitation pattern scaling methodologies and robustness among CMIP5 models, Geosci. Model Dev., 10, 1889-1902, https://doi.org/10.5194/gmd-10-1889-2017, 2017.

Lopez, A., Suckling, E. B., and Smith, L. A.: Robustness of pattern scaled climate change scenarios for adaptation decision support, Climatic Change, 122, 555-566, https://doi.org/10.1007/s10584013-1022-y, 2014.

Lynch, C., Hartin, C., Bond-Lamberty, B., and Kravitz, B.: Exploring global surface temperature pattern scaling methodologies and assumptions from a CMIP5 model ensemble, Geosci. Model Dev. Discuss., https://doi.org/10.5194/gmd-2016-170, 2016.

Mitchell, T. D.: Pattern scaling: an examination of the accuracy of the technique for describing future climates, Climatic Change, 60, 217-242, https://doi.org/10.1023/A:1026035305597, 2003.

O’Neill, B. C., Oppenheimer, M., Warren, R., Hallegatte, S., Kopp, R. E., Pörtner, H. O., Scholes, R., Birkmann, J., Foden, W., Licker, R., Mach, K. J., Marbaix, P., Mastrandrea, M. D., Price, J., Takahashi, K., van Ypersele, J.-P., and Yohe, G.: IPCC reasons for concern regarding climate change risks, Nat. Clim. Change, 7, 28-37, https://doi.org/10.1038/nclimate3179, 2017.

Orlowsky, B. and Seneviratne, S.: Global changes in extreme events: regional and seasonal dimension, Climatic Change, 110, 669-696, https://doi.org/10.1007/s10584-011-0122-9, 2012.

Orlowsky, B. and Seneviratne, S. I.: Elusive drought: uncertainty in observed trends and short- and long-term CMIP5 projections, Hydrol. Earth Syst. Sci., 17, 1765-1781, https://doi.org/10.5194/hess-17-1765-2013, 2013.

Pendergrass, A. G., Lehner, F., Sanderson, B. M., and Xu, Y.: Does extreme precipitation intensity depend on the emissions scenario?, Geophys. Res. Lett.-Atmos., 42, 2015GL065854, https://doi.org/10.1002/2015GL065854, 2015.

Schleussner, C.-F., Lissner, T. K., Fischer, E. M., Wohland, J., Perrette, M., Golly, A., Rogelj, J., Childers, K., Schewe, J., Frieler, K., Mengel, M., Hare, W., and Schaeffer, M.: Differential climate impacts for policy-relevant limits to global warming: the case of $1.5^{\circ} \mathrm{C}$ and $2{ }^{\circ} \mathrm{C}$, Earth Syst. Dynam., 7, 327-351, https://doi.org/10.5194/esd-7-327-2016, 2016.

Screen, J. A.: Arctic amplification decreases temperature variance in northern mid- to high-latitudes, Nat. Clim. Change, 4, 577582, https://doi.org/10.1038/nclimate2268, 2014.

Seneviratne, S., Nicholls, N., Easterling, D., Goodess, C., Kanae, S., Kossin, J., Luo, Y., Marengo, J., McInnes, K., Rahimi, M., Reichstein, M., Sorteberg, A., Vera, C., and Zhang, X.: Changes in climate extremes and their impacts on the natural physical environment, in: Managing the Risks of Extreme Events and Disasters to Advance Climate Change Adaptation, edited by: Field, C., Barros, V., Stocker, T., Qin, D., Dokken, D., Ebi, K., Mastrandrea, M., Mach, K., Plattner, G.-K., Allen, S., Tignor, M., and Midg- 
ley, P., Chapt. 3, pp. 109-230, Cambridge University Press, Cambridge, UK and New York, NY, USA, available at: https://www. ipcc.ch/pdf/special-reports/srex/SREX-Chap3_FINAL.pdf (last access: 28 September 2017), 2012.

Seneviratne, S. I., Donat, M. G., Pitman, A. J., Knutti, R., and Wilby, R. L.: Allowable $\mathrm{CO}_{2}$ emissions based on regional and impact-related climate targets, Nature, 529, 477-483, https://doi.org/10.1038/nature16542, 2016.

Sillmann, J., Kharin, V. V., Zhang, X., Zwiers, F. W., and Bronaugh, D.: Climate extremes indices in the CMIP5 multimodel ensemble: Part 1. Model evaluation in the present climate, J. Geophys. Res.-Atmos., 118, 1716-1733, https://doi.org/10.1002/jgrd.50203, $2013 \mathrm{a}$.

Sillmann, J., Kharin, V. V., Zwiers, F. W., Zhang, X., and Bronaugh, D.: Climate extremes indices in the CMIP5 multimodel ensemble: Part 2. Future climate projections, J. Geophys. Res.-Atmos., 118, 2473-2493, https://doi.org/10.1002/jgrd.50188, 2013b.

Taylor, K. E., Stouffer, R. J., and Meehl, G. A.: An overview of CMIP5 and the experiment design, B. Am. Meteorol. Soc., 93, 485-498, https://doi.org/10.1175/BAMS-D-11-00094.1, 2012.
Tebaldi, C. and Arblaster, J. M.: Pattern scaling: Its strengths and limitations, and an update on the latest model simulations, Climatic Change, 122, 459-471, https://doi.org/10.1007/s10584013-1032-9, 2014.

Vicente-Serrano, S. M., Beguería, S., and López-Moreno, J. I.: A multiscalar drought index sensitive to global warming: the Standardized Precipitation Evapotranspiration Index, J. Climate, 23, 1696-1718, https://doi.org/10.1175/2009JCLI2909.1, 2010.

Whan, K., Zscheischler, J., Orth, R., Shongwe, M., Rahimi, M., Asare, E. O., and Seneviratne, S. I.: Impact of soil moisture on extreme maximum temperatures in Europe, Weather Clim. Extrem., 9, 57-67, https://doi.org/10.1016/j.wace.2015.05.001, 2015.

Wilks, D. S.: "The Stippling Shows Statistically Significant Grid Points": How research results are routinely overstated and overinterpreted, and what to do about it, B. Am. Meteorol. Soc., 97, 2263-2273, https://doi.org/10.1175/BAMS-D-15-00267.1, 2016. 